\title{
Highly Stretchable and Flexible Melt Spun Thermoplastic Conductive Yarns for Smart Textiles
}

\author{
G. M. Nazmul Islam ${ }^{1}$, Stewart Collie ${ }^{2}$, Muhammad Qasim ${ }^{1}$ (D) and M. Azam Ali ${ }^{1, *}$ \\ 1 Centre for Bioengineering \& Nanomedicine, Department of Food Science, Division of Sciences, \\ University of Otago, P.O. Box 56, Dunedin 9054, New Zealand; \\ nazmul.islam@postgrad.otago.ac.nz (G.M.N.I.); muhammadqasim.qasim@otago.ac.nz (M.Q.) \\ 2 Bioproduct \& Fiber Technology, AgResearch, Christchurch 8140, New Zealand; \\ stewart.collie@agresearch.co.nz \\ * Correspondence: azam.ali@otago.ac.nz
}

Received: 16 October 2020; Accepted: 20 November 2020; Published: 24 November 2020

\begin{abstract}
This study demonstrates a scalable fabrication process for producing biodegradable, highly stretchable and wearable melt spun thermoplastic polypropylene (PP), poly(lactic) acid (PLA), and composite (PP:PLA $=50: 50)$ conductive yarns through a dip coating process. Polydopamine (PDA) treated and poly(3,4-ethylenedioxythiophene):poly(styrenesulfonate) (PEDOT:PSS) coated conductive PP, PLA, and PP/PLA yarns generated electric conductivity of $0.75 \mathrm{~S} / \mathrm{cm}, 0.36 \mathrm{~S} / \mathrm{cm}$ and $0.67 \mathrm{~S} / \mathrm{cm}$ respectively. Fourier Transform Infrared Spectroscopy (FTIR) confirmed the interactions among the functional groups of PP, PLA, PP/PLA, PDA, and PEDOT:PSS. The surface morphology of thermoplastic yarns was characterized by optical microscope and Scanning Electron Microscope (SEM). The mechanical properties of yarns were also assessed, which include tensile strength (TS), Young's modulus and elongation at break (\%). These highly stretchable and flexible conductive PP, PLA, and PP/PLA yarns showed elasticity of $667 \%, 121 \%$ and $315 \%$ respectively. The thermal behavior of yarns was evaluated by differential scanning calorimetry (DSC) and thermo-gravimetric analysis (TGA). Wash stability of conductive yarns was also measured. Furthermore, ageing effect was determined to predict the shelf life of the conductive yarns. We believe that these highly stretchable and flexible PEDOT:PSS coated conductive PP, PLA, and PP/PLA composite yarns fabricated by this process can be integrated into textiles for strain sensing to monitor the tiny movement of human motion.
\end{abstract}

Keywords: thermoplastic polymer; melt spinning; thermoplastic yarn; electric conductivity; wearable textile

\section{Introduction}

Smart textiles have drawn increased attention from the academic researchers and industry people due to their high sensitivity, high flexibility, breathability, multitasking capability, availability, low cost, deformability and comfort [1-5]. Textiles can be conductive applying various methods including spinning [6-9], knitting [10], coating [11-15], screen printing [16], inkjet printing [17,18] and 3D printing [19-22]. Electrically conductive yarn is one of the most basic and essential components of smart textiles due to its light weight, high stretchability, elasticity, flexibility, and comfort [23,24]. Integrating electronic mechanisms into textile structures can impart various smart functionalities including sensing, monitoring tiny body movement and information processing to conventional clothing [25].

Poly(lactic acid) (PLA) is one of the most promising and cheapest bio-based materials among the various biodegradable polyesters available in the market such as polyglycolic acid (PGA), 
polyhydroxybutyrate (PHB), and polycaprolactone (PCL) due to easy process characteristics [26,27]. PLA has been used in the field of biomedical, medical textiles, agricultural textiles, geo-textiles, food industry, filters, towels, home furnishings, industrial fabrics, and personal belongings due to their natural origin, adequate mechanical properties, permeability, low flammability, and excellent UV resistance [28]. Polypropylene (PP), an outstanding semi crystalline and non-polar thermoplastic polymer has been used in a wide range of applications such as protective textiles, geo-textiles, automotive interior, filaments, furniture, antistatic materials, medical devices, soft tissue replacement, plastic, piping systems, and other consumer food packaging due to its low cost, availability, gas barrier properties, adequate mechanical properties, and thermo-plasticity [29-31]. However, the use of PLA is restricted to the biomedical and packaging applications due to slow degradation, high processing cost and low shelf life though PLA shows high rigidity and good biocompatibility [30]. The main limitations of PLA, including low toughness and high brittleness, limit its application in stressful conditions [32,33]. It is a great challenge to achieve high levels of toughness of PLA film. The properties of PLA can be modified by blending, plasticization, and/or by reactive processing [34]. Blending polymer with other nanoparticles or polyolefin polymers is a simple method to potentially improve the property of pure polymer [35]. To minimize the above limitations of PLA, the blending of PLA with PP can lead to the desired properties such as high productivity and quick formulation changes at low price. Blending of PLA, starch, polyethylene glycol, polyethylene oxide, and polycaprolactone (PCL) with PP improves the degradability of PP. This polymer blending and composite have been widely used in biomedical textile, medical packaging, energy storage, plastic industries, and food packaging industries due to its enhanced mechanical, thermal, electrical, and biodegradation properties [36,37]. Introduction of PP with PLA decreases the stiffness property of PLA and thus enhance the mechanical properties of composite yarn. In this present investigation, melt spinning was applied to produce PP, PLA, and blend PP/PLA thermoplastic yarns due to low investment cost, solvent free simple spinning process, high production rate, and no environmental pollution. Melt spun PP, PLA, and blend PP/PLA yarns are hydrophobic and act as insulators. PP, PLA, and blend PP/PLA yarns do not absorb any chemical during coating due to hydrophobicity. Surface modifications play a vital role in a variety of application domains from electronics to medicine including interfacing with cells, bio-sensing, and drug delivery [38]. Polydopamine (PDA), a dopamine derived synthetic eumelanin polymer, can modify many kinds of substrates [12,39]. Polydopamine acts as a universal surface modification agent for different applications such as nanotechnology [40], biotechnology [41]. Here all thermoplastic yarns were treated with dopamine and Tris $\mathrm{HCl}$ solution. This PDA treatment converted hydrophobic yarns into hydrophilic which was proved by contact angle (CA) analysis.

Inherently conducting polymers (ICPs) such as polypyrrole, PEDOT, and polyaniline have become popular choices for producing multi-functional fibers, films, and fabrics because of their high conductivity, excellent electrochemical properties, promising catalytic activity, ease of handling, and excellent solution processability [42-50]. PEDOT:PSS is an automatic choice for researchers due to its high conductivity and high stability for developing highly conductive and flexible sensors for various applications such as biomedical and limb motion sensing [51], $\mathrm{pH}$ sensing [52,53], flexible heating element on textiles [54], strain sensing [14,55,56], temperature sensing [57], and wearable e-textiles [58]. Martin et al. [59] developed a multi-walled carbon nanotube (MWCNT, 4\%)/polyethylene (PE) conducting polymeric composite by melt spinning technique and achieved conductivity only $0.1 \mathrm{~S} / \mathrm{cm}$. Soroudi et al. [60] also demonstrated filaments of blends of polypropylene (PP)/polyaniline (PANI) $(20 \mathrm{wt} \%) / M W C N T(7.5 \mathrm{wt} \%)$ by melt spinning and this blend filaments showed maximum conductivity about $0.16 \mathrm{~S} / \mathrm{cm}$. Wang et al. [61] developed a PEDOT:PSS/PVA composite fiber via wet-spinning process for increasing the electrical conductivity and thermal stability but no information of washing is available. In this experiment, these conductive thermoplastic yarns were rinsed and the effect of rinsing on electric conductivity was assessed. These developed thermoplastic yarns also showed better electrical conductivity, thermal, and mechanical stability compared to others, which is suitable for strain sensing. 
The target of this experiment is to fabricate PEDOT:PSS coated stable conductive thermoplastic PP, PLA and blend PP/PLA yarn which is free of metal, carbon, and silica nanoparticles. For predicting and analyzing the aging properties of conductive yarns, the aging behavior was assessed. Figure 1a,b show the key possible chemical reaction steps for producing PDA treated and PEDOT:PSS coated conductive PP and PLA yarns respectively.

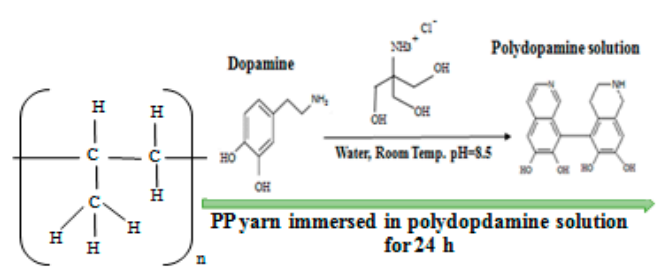

PP yarn

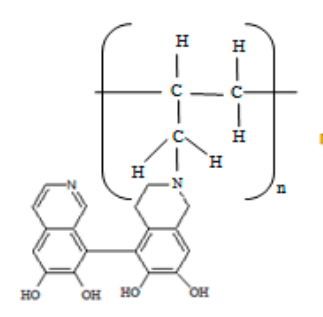

PDA treated PP yarn
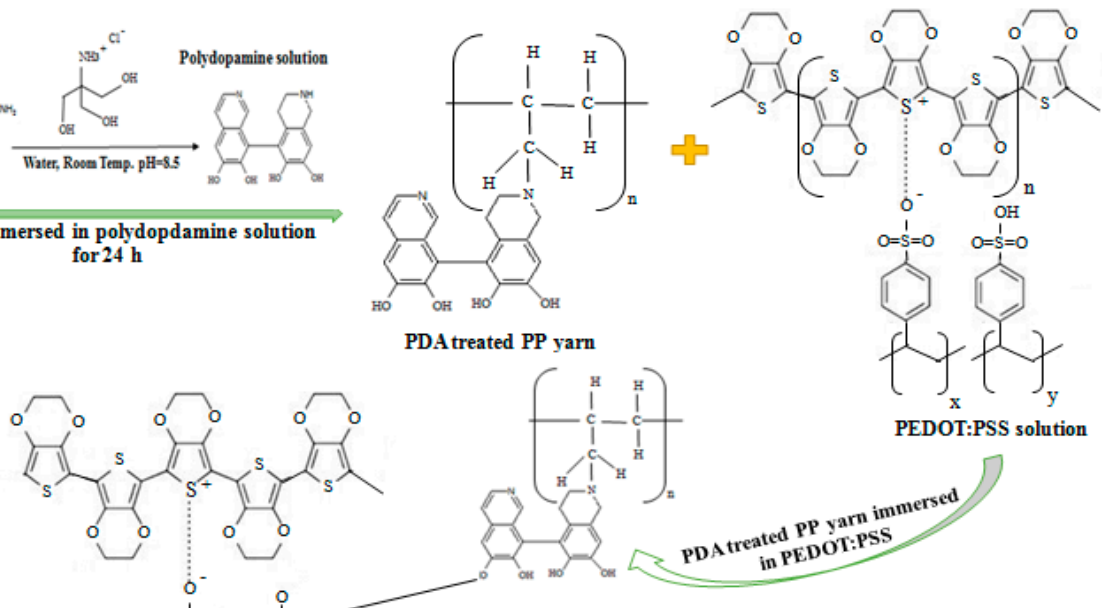

PEDOT:PSS solution

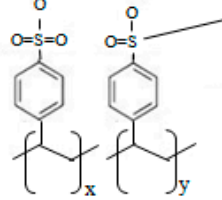

PEDOT:PSS coated conductive PP yarn

(a)

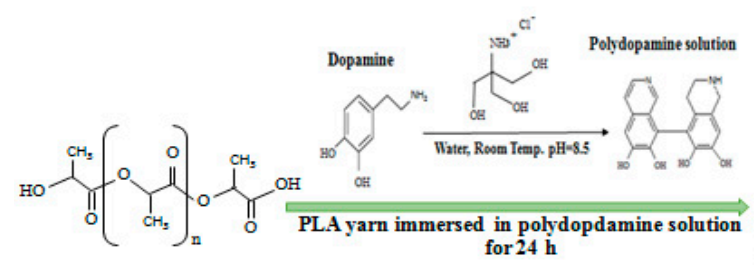

PLA yarn for $24 \mathrm{~h}$

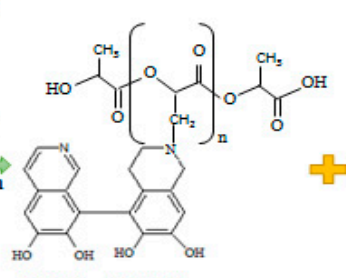

PDA treated PLA yarn

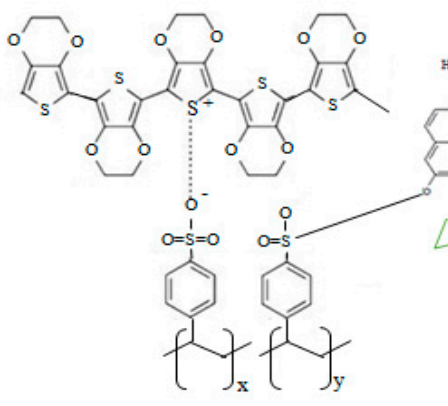

PEDOT:PSS coated conductive PLA yarn

(b)

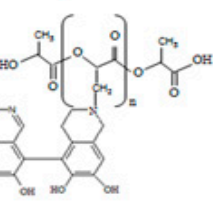

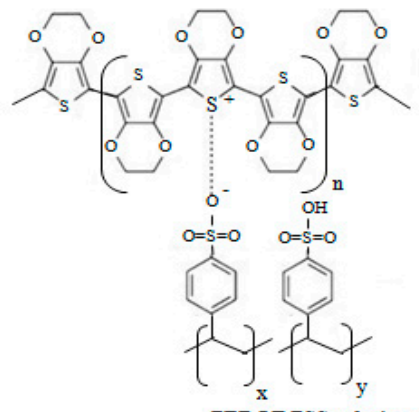

PEDOT:PSS solution PDAtreated PLA yarn im
PEDOT:PSS
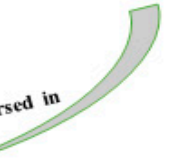


\section{Materials and Methods}

\subsection{Materials}

A melt spinner (LE-075 Mixing Extruder, CSI, USA) shown in Figure 2 was used for producing thermoplastic melt spun yarns. Poly (lactic acid) (PLA) was provided by Imagin Plastics Ltd., Auckland, New Zealand (average molecular weight, Mw 2.08 $\times 10^{5}$, melt flow index, MFI 210 ${ }^{\circ} \mathrm{C} / 2.16 \mathrm{~kg}$ of $15-25 \mathrm{~g} / 10 \mathrm{~min})$. Polypropylene (PP) was procured from Lyondell Basell, New Zealand $\left(\mathrm{Mw} \sim 2.20 \times 10^{5}\right.$, MFI $230{ }^{\circ} \mathrm{C} / 2.16 \mathrm{~kg}$ of $\left.25 \mathrm{~g} / 10 \mathrm{~min}\right)$. PEDOT:PSS dispersion was purchased from Sigma-Aldrich, New Zealand with a ratio of PSS:PEDOT $=1: 1.5, \mathrm{pH}=2-3.5$ used as conducting material. Tris hydrochloride (Tris $\mathrm{HCl}$ ) (Bio-Froxx, GmbH, Germany) was used as buffer agent and dopamine hydrochloride (98\%, Sigma-Aldrich, New Zealand) was used as binding agent for surface modification of thermoplastic yarn. Hydrochloric acid ( $\mathrm{HCl})$ (Sigma-Aldrich, New Zealand) was used to maintain $\mathrm{pH}=8.5$ for dopamine and Tris $\mathrm{HCl}$ solution.

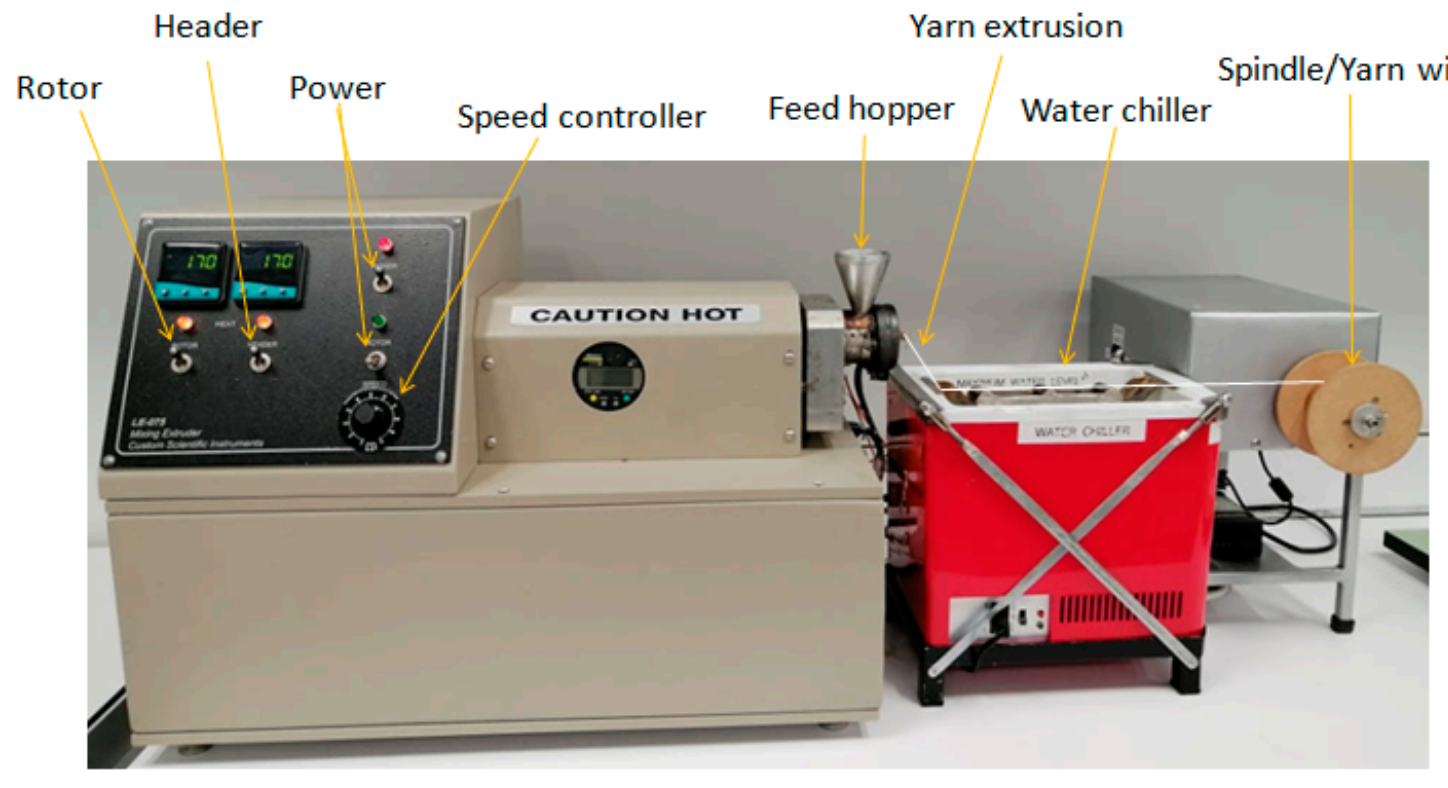

Figure 2. Schematic diagram of LE-075 Mixing Extruder.

\subsection{Preparation of Melt Spun Conductive Composite Yarns}

Before thermoplastic yarn extrusion, the most important parameters such as melting point of filler and matrix, resident time, rotation per minute (rpm) for the extruder were identified. Speed/output voltage of the extruder plays a vital role for maintaining the same diameter of the fine filament. Thermoplastic yarns were produced by identifying and applying the melting point of the fillers and rpm of extrusion. In this experiment, the resident time, rpm, and speed/output voltage for the extruder were $3 \mathrm{~min}, 90$ and $50 \mathrm{~V}$ respectively. In this present investigation, three (3) types of thermoplastic yarns were developed maintaining the residence time, voltage percentage, and rpm of extruder. Figure $3 a-c$ illustrate the schematic diagram of PDA treated and PEDOT:PSS coated melt spun PP, PLA, and blend PP/PLA conductive yarns respectively. At first PP and PLA thermoplastic melt spun yarns were produced by a melt extruder at $170{ }^{\circ} \mathrm{C}$ and $155^{\circ} \mathrm{C}$ respectively. Then a mixture (50\% PP and 50\% PLA) of thermoplastic polymers was manually measured and mixed and also put into the hopper of the extruder. Considering the melting point of PP and PLA, the composite thermoplastic melt spun yarn was extruded at $170{ }^{\circ} \mathrm{C}$. For uniform blending, the produced composite yarn was cut into small sections using a scissor and again put into the feed hopper. Maintaining the same temperature, rpm, and voltage percentage of the extruder, the final composite (PP/PLA) yarn was produced by repeating this process for two times. It is mentioned that considering the residence time ( $3 \mathrm{~min}), \mathrm{rpm}(90)$ and output voltage $(50 \mathrm{~V})$ of the melt extruder, the take up speed of uniform yarn production is approximately $1 \mathrm{~m} / \mathrm{min}$. 
The take up speed of yarn production can be increased by increasing the speed/output voltage of the melt extruder.

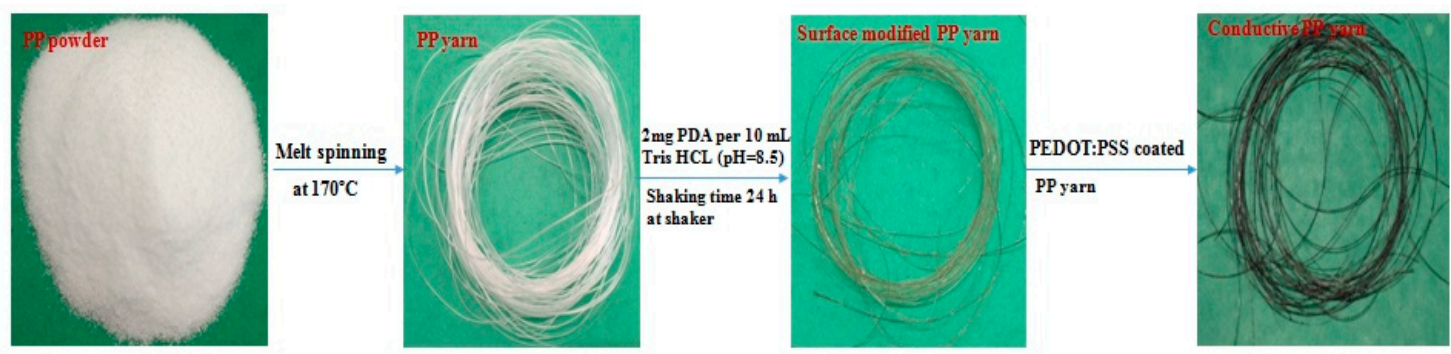

(a)

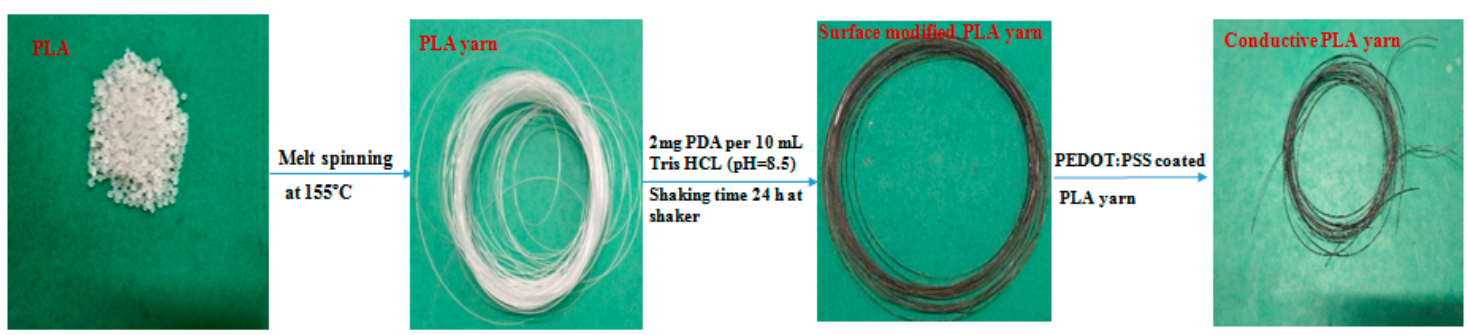

(b)
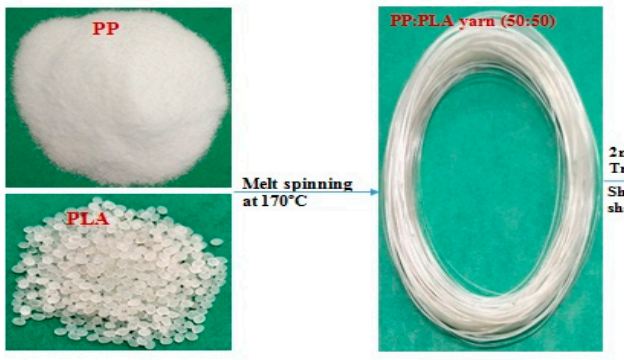

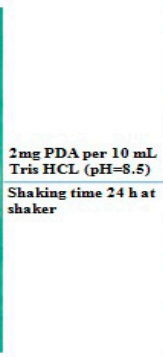

(c)

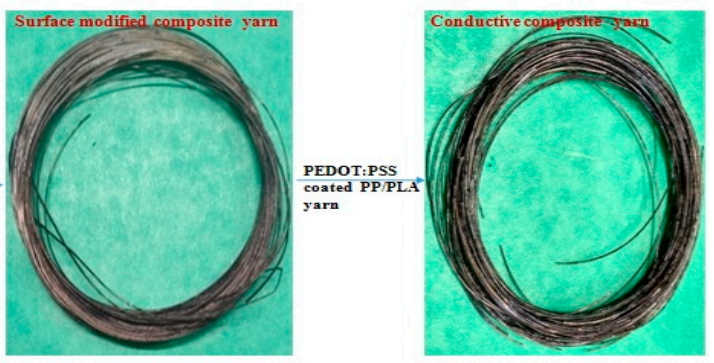

Figure 3. Schematic diagram of PEDOT:PSS coated conductive (a) PP, (b) PLA and (c) blend PP/PLA yarn.

These hydrophobic yarns were chemically modified to increase the hydrophilicity with PDA and Tris $\mathrm{HCl}$. $12.11 \mathrm{~g}$ Tris $\mathrm{HCl}$ was added in $80 \mathrm{~mL}$ distilled water and $\mathrm{pH}=8.5$ was maintained by gently adding $1 \mu \mathrm{M}$ of hydrochloric acid $(\mathrm{HCl})$ for producing Tris $\mathrm{HCl}$ solution. $2 \mathrm{mg}$ of dopamine hydrochloride per $10 \mathrm{mM}$ Tris $\mathrm{HCl}$ was added to produce the aqueous solution. PP, PLA, and blend PP/PLA based hydrophobic yarns were immersed in this aqueous solution and kept in a shaker for $24 \mathrm{~h}$ with $55 \mathrm{rpm}$ at room temperature. The surface modified yarns were rinsed with distilled water for 1 min and line dried at room temperature. These PDA treated hydrophilic PP, PLA and blend PP/PLA yarns were immersed in PEDOT:PSS dispersion for $5 \mathrm{~min}$. Then the coated yarns were dried at room temperature for $4 \mathrm{~h}$ by hanging them on a clothes line using wooden clip hangers shown in Figure 4 . This coating process was repeated for two dip coating cycles. All the thermoplastic yarns were coated for two times considering the flexibility, stiffness, and rigidity of conductive yarns. Though more coating cycles increased the conductivity but made the yarns stiff and rigid. Stiff and rigid yarns are not suitable for integrating into textiles for wearable applications. The above fabrication process can be described as: production of thermoplastic yarns by melt spinning $>$ surface modification by polydopamine > PEDOT:PSS coated conductive yarns by dip coating. 


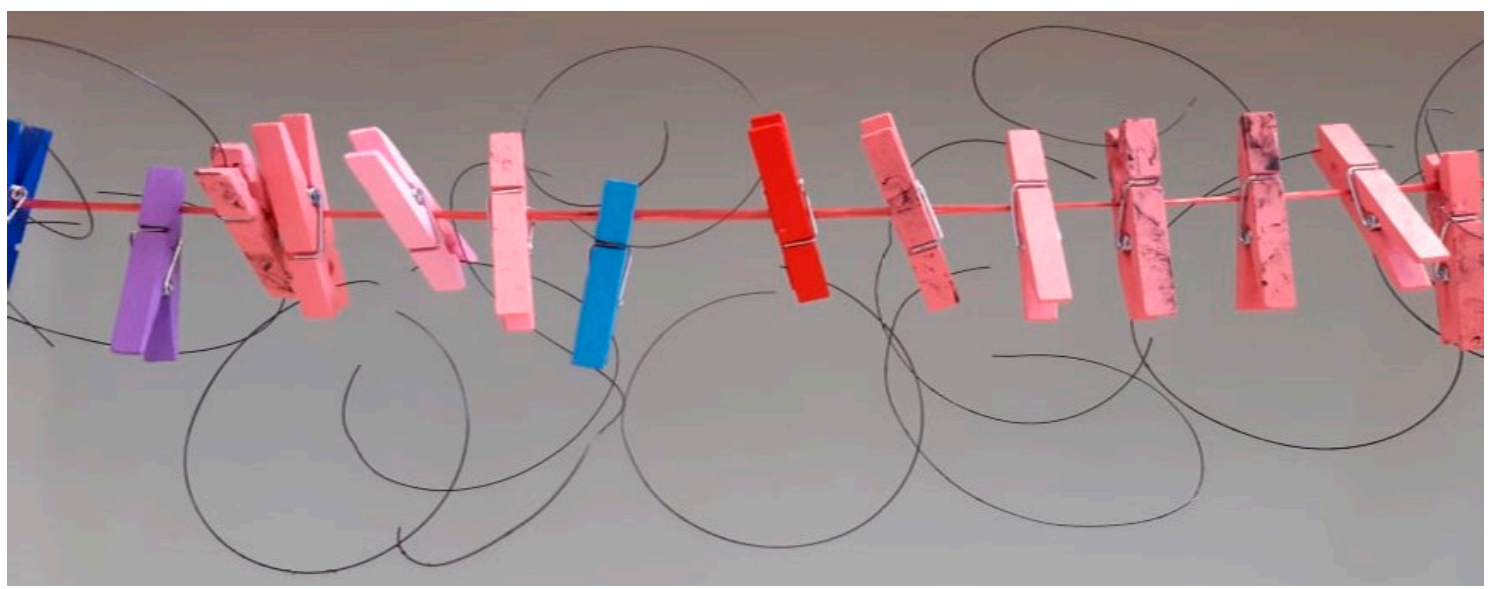

Figure 4. Line drying system for drying PEDOT:PSS coated conductive yarns.

\subsection{Characterizations of Thermoplastic Yarns}

The chemical interactions among different components such as pure PP, pure PLA, blend PP/PLA, PDA, and PEDOT:PSS were studied using FTIR. This measurement was performed with a total of 24 scans/sample over the range of $4000-400 \mathrm{~cm}^{-1}$ at resolution of $4 \mathrm{~cm}^{-1}$.

The contact angle (CA) was analyzed using FTA200 Dynamic Contact Angle Analyzer (First Ten Angstroms, Portsmouth, VA, USA) with the static sessile drop method. A droplet ( $1 \mu \mathrm{L})$ of distilled water was placed on the surface of the raw thermoplastic and PDA treated yarns by a syringe. A video camera (Sony ICX274 CCD) was used to record the water contact angles of the raw thermoplastic and PDA treated yarns at room temperature.

The DC electrical resistance of $20 \mathrm{~cm}$ lengths of conductive yarns was measured by FLUKE 114 TRUE RMS Multimeter (Everett, WA, USA) before and after rinsing. Electric resistance was measured three times for each conductive yarn every after each dip coating cycle and averaged. Then electric conductivity $(\sigma)$ was measured applying the following formula [62]:

$$
\sigma=\mathrm{L} / \mathrm{RA}
$$

where R is the electrical resistance $(\Omega)$, A is the total cross-sectional surface area $\left(\mathrm{cm}^{2}\right)$ and L is the distance between electrodes $(\mathrm{cm})$.

Optical microscopy was performed on several pure PP, pure PLA, blend PP/PLA, surface modified, and PEDOT:PSS coated yarns to determine the presence of PDA and conductive polymer on pure yarns. Each yarn was attached at both sides on a glass slide using clear scotch tape exposing $30 \mathrm{~mm}$ of yarn. Optical microscopy was carried out by an optical microscope (OLYMPUS, Tokyo, Japan). Optical images were captured with a HUWAEI Y9 camera (Shenzhen, China) and images were cropped using Photoshop software. An image of the all yarns at 100 times magnification was captured in all stages in the same position.

For analyzing the yarn surface morphology, PDA treated and PEDOT:PSS coated samples were attached to the scanning electron microscope (SEM) specimen stub using double sided carbon tape. Before SEM analysis, they were sputter-coated with $5 \mathrm{~nm}$ gold-palladium using a Q150T sputter coater (Quorum Technologies Ltd., East Sussex, UK) in order to prevent the surface charging effect which gives a blurred picture and to promote the emission of secondary electrons for providing a homogeneous surface for analysis. This morphological analysis of yarns was characterized using Tabletop Microscope TM3030 (Hitachi, Japan) with voltage of $15 \mathrm{kV}$ at different magnifications. The thickness of the coating was measured using ImageJ software by taking three measurements of six different samples of the coatings. Data are expressed as mean \pm SD. 
The washing stability of conductive yarns of each dip cycle was assessed. The coated conductive yarns of each dip cycle were rinsed for $1 \mathrm{~min}$ and line dried for $2 \mathrm{~h}$ at room temperature. Then their electrical resistance was measured. This rinsing process was carried out five times.

Differential Scanning Calorimetry (DSC) was performed by TA analyzer (TA) Q1000 instrument (TA Instruments, New Castle, DE, USA) to measure the glass transition $\left(\mathrm{T}_{\mathrm{g}}\right)$ and melting $\left(\mathrm{T}_{\mathrm{m}}\right)$ temperature characteristics of thermoplastic PP, PLA, and blend PP/PLA conductive yarns to determine the thermal stability. Samples were weighed $(10-15 \mathrm{mg}$ ) into a pan (Tzero pan; TA Instruments Ltd., New Castle, DE, USA). Each sample was heated over the temperature range from 20 to $200{ }^{\circ} \mathrm{C}$ at the rate of $5{ }^{\circ} \mathrm{C} / \mathrm{min}$ under nitrogen atmosphere $(50 \mathrm{~mL} / \mathrm{min})$.

The thermal stability and degradation of pure PP, pure PLA, PP/PLA, PDA treated and PEDOT:PSS coated yarns were analyzed by Q50 TGA analyzer (TA instruments, New Castle, DE, USA). The weight of samples was $20-35 \mathrm{mg}$. These stability analyses were performed over the temperature range 200 to $600{ }^{\circ} \mathrm{C}$ at a heating rate $20^{\circ} \mathrm{C} / \mathrm{min}$ under the nitrogen atmosphere $(20 \mathrm{~mL} / \mathrm{min})$.

The mechanical properties of all yarns were investigated by a TA.HD plusC Texture Analyzer (UK) applying $5 \mathrm{~kg}$ load cell, gauge length of $25 \mathrm{~mm}$ and tensile speed $20 \mathrm{~mm} / \mathrm{min}$ at room temperature.

To evaluate the aging effect, the conductive yarns of each dipping cycle were stored in a ambient room conditions for five weeks in separate polythene bags with minimal exposure to air and moisture. The loss of electrical resistance during aging was measured every week in order to determine the shelf life of conductive yarn.

\section{Results and Discussion}

\subsection{Fourier Transform Infrared Spectroscopy (FTIR) Analysis}

The functional groups of all the samples such as pure PP, pure PLA, blend PP/PLA, PDA and PEDOT:PSS were confirmed by interpretation of the FTIR spectra. Figure $5 a$, Figure $5 b$, and Figure $5 c$ represent the FTIR spectra of PDA treated and PEDOT:PSS coated conductive PP, PLA and PP/PLA yarns respectively. All the transmittance bands are also listed in Table 1. Here Figure 5a depicts the transmittance bands corresponding to PP at $2950-2850 \mathrm{~cm}^{-1}, 1454 \mathrm{~cm}^{-1}$ and $1377 \mathrm{~cm}^{-1}$ were assigned to $\mathrm{C}-\mathrm{H}$ stretching, $-\mathrm{CH}_{3}$ bending and $\mathrm{C}-\mathrm{H}$ bending respectively [30]. Here Figure $5 \mathrm{~b}$ depicts the FTIR spectra of PLA, transmittance bands at 2995-2945 cm $-1749 \mathrm{~cm}^{-1}, 1182-1045 \mathrm{~cm}^{-1}$ and $1453 \mathrm{~cm}^{-1}$ referred to $\mathrm{CH}$ and $\mathrm{CH}_{3}$ group, $\mathrm{C}=\mathrm{O}$ stretching, symmetric $\mathrm{C}-\mathrm{O}-\mathrm{C}$ stretching and asymmetric bending absorption of $\mathrm{CH}_{3}$ respectively [63]. Ploypeetchara et al. [64] analyzed the spectra of different PP/PLA ratios and found the transmittance bands that represent PP and PLA were observed in the PP/PLA blend around $2952-2848 \mathrm{~cm}^{-1}, 1456-1454 \mathrm{~cm}^{-1}, 1376 \mathrm{~cm}^{-1}, 1183-1182 \mathrm{~cm}^{-1}$ and $1086-1184 \mathrm{~cm}^{-1}$. A specific peak for all PP/PLA blends appeared at $1749 \mathrm{~cm}^{-1}$ is corresponded to the stretching of the ester group $(-\mathrm{COO})$ where the chemical interaction of the anhydride group of PP with the carbonyl group of PLA formed a new linkage which indicates the PP/PLA blends [37]. From Figure 5c, the transmittance bands that represent PP and PLA were observed in the PP/PLA blends around 2950-2848 $\mathrm{cm}^{-1}$, $1743 \mathrm{~cm}^{-1}, 1454 \mathrm{~cm}^{-1}, 1376 \mathrm{~cm}^{-1}$ and $1182 \mathrm{~cm}^{-1}$. After surface modification of PP, PLA and PP/PLA by PDA, the transmittance bands at $3186-3345 \mathrm{~cm}^{-1} ; 3184-3345 \mathrm{~cm}^{-1}$ and $3184-3345 \mathrm{~cm}^{-1}$ respectively corresponded to stretching vibrations of $\mathrm{O}-\mathrm{H}$ and $\mathrm{N}-\mathrm{H}$ groups of PDA [65]. 


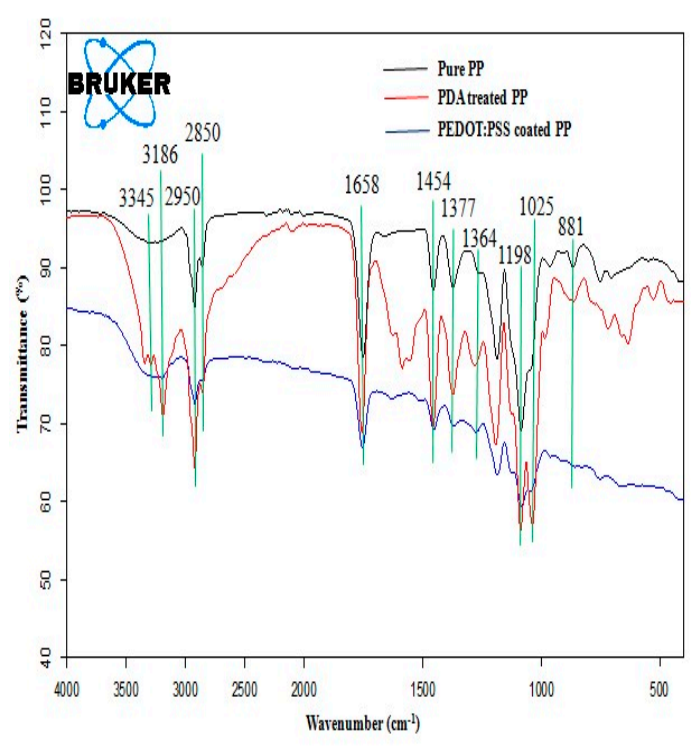

(a)

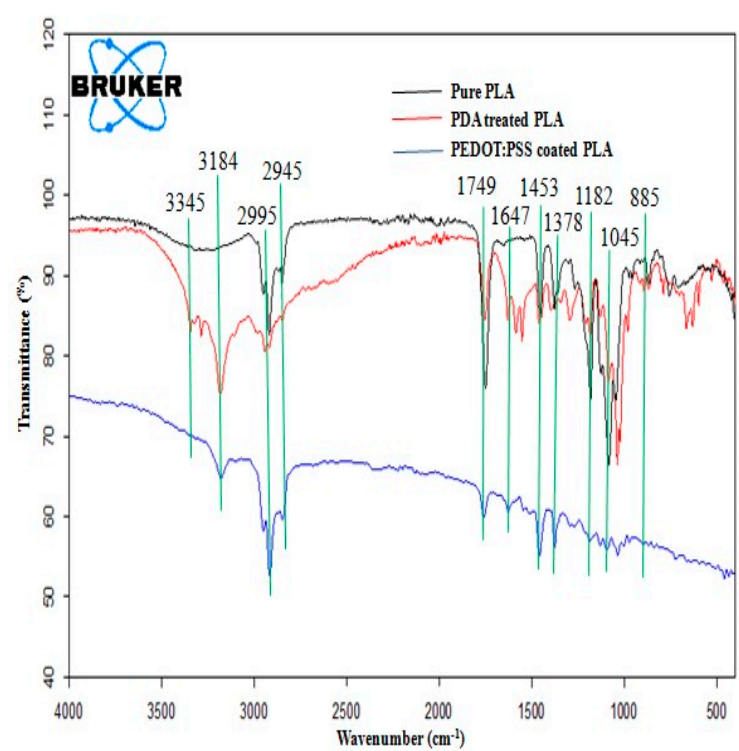

(b)

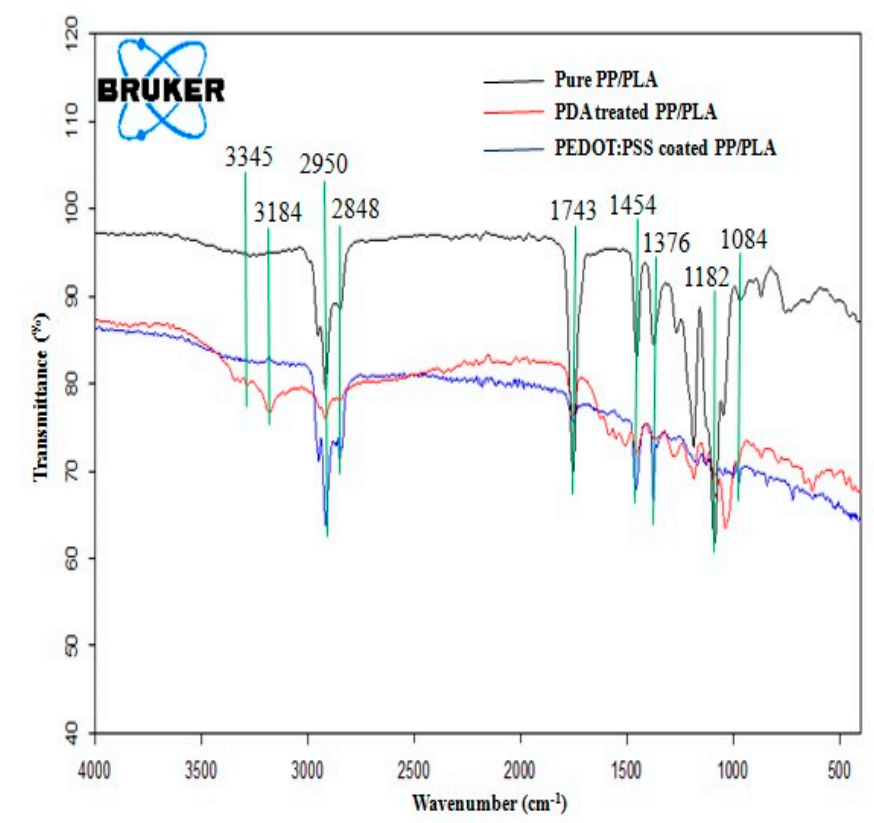

(c)

Figure 5. FTIR spectra of PEDOT:PSS coated (a) PP, (b) PLA and (c) blend PP/PLA yarn.

Table 1. FTIR transmittance bonds of thermoplastic yarns.

\begin{tabular}{cc}
\hline IR Absorption Bands $\mathbf{( \mathbf { c m } ^ { - 1 } )}$ & Description \\
\hline $3184-3345$ & stretching vibrations of O-H and N-H \\
$2945-2850$ & groups \\
$1743-1454$ & $\mathrm{C}-\mathrm{H}$ stretching \\
$1647-1658$ & $-\mathrm{CH}_{3}$ stretching \\
$1045-1182$ & $\mathrm{C}=\mathrm{C}$ stretching \\
1376 & $\mathrm{C}=\mathrm{O}$ stretching \\
1183 and $1025-881$ & $\mathrm{C}-\mathrm{H}$ bending \\
1453 & Stretching C-S \\
\hline
\end{tabular}


From Figure $5 \mathrm{a}-\mathrm{c}$, it is seen that the PDA was coated successfully onto the surfaces of PP, PLA and PP/PLA yarns. From Figure 5a it is seen that the absorption spectra of PEDOT:PSS coating on PDA treated conductive polypropylene yarn displayed the polymeric interactions in the thiophene backbone including $C=C, C-C$ and $C-S$ bonds at $1658 \mathrm{~cm}^{-1}, 1364 \mathrm{~cm}^{-1}, 1198 \mathrm{~cm}^{-1}$ and $1025-881 \mathrm{~cm}^{-1}$ respectively [63]. Similarly Figure $5 \mathrm{~b}$ shows that the FTIR spectra of PEDOT:PSS coated and PDA treated conductive PLA yarn displayed the polymeric interactions in the thiophene back bone, including $\mathrm{C}=\mathrm{C}$, C-C and C-S bonds at $1647 \mathrm{~cm}^{-1}, 1378 \mathrm{~cm}^{-1}, 1199 \mathrm{~cm}^{-1}$ and $1025-885 \mathrm{~cm}^{-1}$ respectively [63]. Figure 5c also indicates that the absorption spectra of PDA treated and PEDOT:PSS coated conductive PP/PLA yarn displayed the transmittance bands at $1647 \mathrm{~cm}^{-1}, 1376 \mathrm{~cm}^{-1}, 1183 \mathrm{~cm}^{-1}$ and $1084-1042 \mathrm{~cm}^{-1}$ corresponded to $C=C, C-C$ and $C-S$ bonds respectively [66]. From Figure $5 a-c$, it is confirmed that after two coating layers of PEDOT:PSS on PDA treated PP, PLA, and PP/PLA yarns, all transmittance bands were found to be almost similar due to low PSS adsorption.

\subsection{Contact Angle (CA) Analysis}

Wettability, an important phenomena of substrates which is related to the surface roughness and surface charge. Here the melt spun thermoplastic yarns do not absorb any chemicals due to their hydrophobicity. Using the general method of contact angle measurement, it is hard to analyze a tiny fiber and yarn. Therefore, we modified the procedure and used adhesive tape to put yarn on contact angle machine stage. For dropping water on yarn surface, we did not use the machine connected syringe pump. However, we manually placed the drop of water on yarn surface using micro-pipette volume $(1 \mu \mathrm{L})$. The contact angles $(\theta)$ of raw thermoplastic polypropylene yarn and PDA treated polypropylene yarn were measured and shown in Figure 6. From Figure 6, it is seen that the contact angle (CA) of raw thermoplastic polypropylene yarn is $\theta=135^{\circ}$. It has a CA value of $135^{\circ}$ in all groups before surface modification. As this raw thermoplastic polypropylene yarn is hydrophobic, the surface of this yarn was modified by polydopamine. After polydopamine treatment, the CA of treated polypropylene yarn decreased which is $\theta=60^{\circ}$. From the CA of PDA treated yarn, it is confirmed that PDA converted hydrophobic thermoplastic polypropylene yarns into hydrophilic.

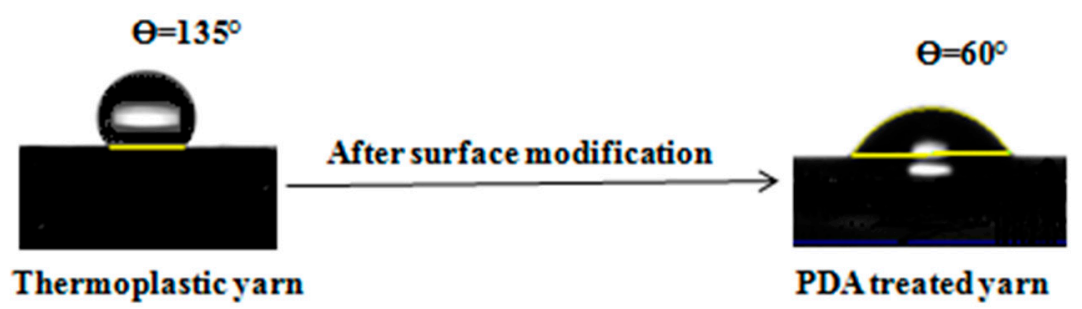

Figure 6. The images of water contact angle of untreated and PDA treated thermoplastic yarns.

\subsection{Electrical Conductivity before Rinsing}

Electrical conductivity is one of the most important key aspect and requirements for wearable conductive yarns. Table 2 shows the electric conductivity of PDA treated and PEDOT:PSS coated $20 \mathrm{~cm}$ long conductive PP, PLA, and blend PP/PLA yarns before rinsing. 
Table 2. Electrical conductivity (S/cm) of PEDOT:PSS coated PP, PLA, and blend PP/PLA yarn before rinsing.

\begin{tabular}{|c|c|c|c|c|c|c|c|c|}
\hline \multirow[b]{2}{*}{ Yarn Type } & \multirow{2}{*}{$\begin{array}{l}\text { Radius } \\
\text { (cm) }\end{array}$} & \multirow{2}{*}{$\begin{array}{l}\text { Area } \\
\left(\mathrm{cm}^{2}\right)\end{array}$} & \multirow{2}{*}{$\begin{array}{l}\text { Coating Cycle } 1 \\
\text { Mean Electrical } \\
\text { Resistance }(\mathrm{k} \Omega)\end{array}$} & \multicolumn{5}{|c|}{ Coating Cycle 2} \\
\hline & & & & SD & $\begin{array}{l}\text { Conductivity } \\
(\mathrm{S} / \mathrm{cm})\end{array}$ & $\begin{array}{l}\text { Mean Electrical } \\
\text { Resistance }(\mathrm{k} \Omega)\end{array}$ & SD & $\begin{array}{c}\text { Conductivity } \\
(\mathrm{S} / \mathrm{cm})\end{array}$ \\
\hline PP & 0.014 & 0.000616 & 131.00 & 3.42 & 0.25 & 43.04 & 2.20 & 0.75 \\
\hline PLA & 0.013 & 0.000531 & 223.33 & 7.77 & 0.17 & 122.67 & 5.47 & 0.36 \\
\hline PP/PLA & 0.012 & 0.000452 & 181.13 & 3.62 & 0.24 & 65.93 & 1.23 & 0.67 \\
\hline
\end{tabular}

$\mathrm{SD}=$ Standard Deviation.

After the first and second dip coating cycles, the electric conductivity of conductive PP yarn is $0.25 \mathrm{~S} / \mathrm{cm}$ and $0.75 \mathrm{~S} / \mathrm{cm}$, respectively. Similarly, the electric conductivity of conductive PLA yarn is $0.17 \mathrm{~S} / \mathrm{cm}$ and $0.36 \mathrm{~S} / \mathrm{cm}$ respectively. In addition, the electrical conductivity of blend PP/PLA yarn is 0.24 and $0.67 \mathrm{~S} / \mathrm{cm}$ respectively before rinsing. The number of dip coating cycle increases the electrical conductivity of the coated yarns. After the second coating cycles, the electrical conductivity of each yarn increases at least two times compared to the first coating cycle. In Table 2, it is seen that the PDA treatment has converted the hydrophobic yarns into hydrophilic yarns successfully which was proved by contact angle analysis and the number of coating cycles increased the PEDOT:PSS pick up \% which increased the electrical conductivity.

\subsection{Tensile Properties Analysis}

The mechanical properties (tensile strength, Young's modulus, and elongation at break \%) of pure PP, pure PLA, pure PP/PLA, PDA treated and PEDOT:PSS coated conductive PP, PLA, and PP/PLA yarns were investigated. The role of the PDA introduction and PEDOT:PSS coating on melt spun PP, PLA and PP/PLA yarns was characterized by their mechanical properties. Figure 7 illustrates the stress-strain curves to analyze the mechanical properties of the various types of yarns. Three (3) replicates were tested for each yarn and the average values of tensile strength, Young's modulus and elongation at break (\%) were reported in Table 3.

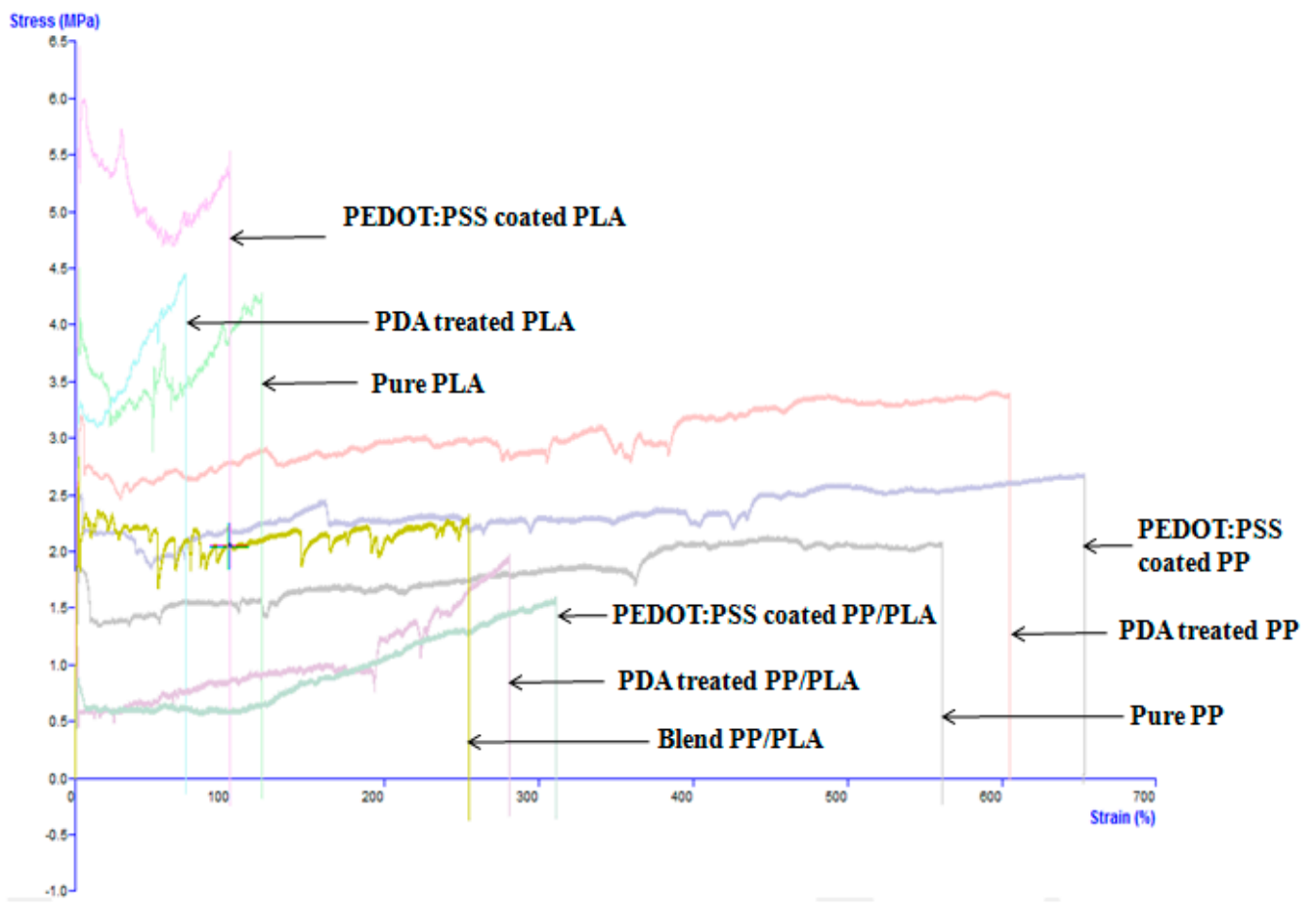

Figure 7. The stress-strain curves of various thermoplastic yarns. 
Table 3. Mechanical properties of thermoplastic yarns.

\begin{tabular}{ccccccc}
\hline Types of Yarn & Tensile Strength (MPa) & $\begin{array}{c}\text { SD } \\
\text { (MPa) }\end{array}$ & $\begin{array}{c}\text { Tensile/Young's } \\
\text { Modulus (MPa) }\end{array}$ & $\begin{array}{c}\text { SD } \\
\text { (MPa) }\end{array}$ & $\begin{array}{c}\text { Elongation at } \\
\text { Break (\%) }\end{array}$ & SD \\
\hline $\begin{array}{c}\text { PP } \\
\text { Modified PP }\end{array}$ & 1.22 & 0.14 & 76.98 & 4.99 & 594.53 & 5.76 \\
$\begin{array}{c}\text { PEDOT:PSS } \\
\text { coated PP }\end{array}$ & 1.81 & 0.09 & 87.92 & 5.47 & 636.51 & 7.98 \\
\hline $\begin{array}{c}\text { PLA } \\
\text { Modified PLA }\end{array}$ & 1.97 & 0.02 & 116.39 & 8.94 & 667.47 & 5.92 \\
PEDOT:PSS & 2.99 & 0.18 & 230.70 & 7.67 & 42.30 & 0.39 \\
coated PLA & 3.41 & 0.40 & 291.87 & 5.78 & 76.89 & 0.63 \\
\hline $\begin{array}{c}\text { PP/PLA } \\
\text { Modified PP/PLA }\end{array}$ & 3.57 & 0.23 & 309.29 & 7.51 & 121.35 & 0.48 \\
$\begin{array}{c}\text { PEDOT:PSS } \\
\text { coated PP/PLA }\end{array}$ & 1.35 & 0.15 & 96.164 & 7.71 & 227.17 & 1.34 \\
\hline
\end{tabular}

$\mathrm{SD}=$ Standard Deviation

Figure 7 shows all full stress-strain curves for analyzing the tensile strength, Young's modulus, and elongation at break\%. From Table 3, it is seen that PLA yarns have better tensile strength compared to PP and PP/PLA yarns. The tensile strength of pure PP, pure PLA, blend PP/PLA, polydopamine treated and PEDOT:PSS coated PP, PLA and PP/PLA is $1.22 \mathrm{MPa}, 1.81 \mathrm{MPa}, 1.97 \mathrm{MPa}$; $.99 \mathrm{MPa}$, 3.41 MPa, 3.57 MPa; and 1.35 MPa, 2.08 MPa, 2.56 MPa respectively. Moreover, the tensile strength of PP/PLA blends improved with the addition of the PLA content due to the higher Young's modulus of the PLA yarn compared to the PP yarn. The bridged two immiscible PP and PLA polymers have formed a strong chemical bond which was confirmed by the FTIR analysis. However, polydopamine treatment and PEDOT:PSS coating also increased the mechanical properties of these treated and coated yarns. The mechanical properties of PP/PLA blends are strongly influenced with greater physical properties of PLA including the degree of crystallinity, melting point, density, heat capacity hardness, Young's modulus, tensile strength, glass transition temperature, and mechanical properties.

From Table 3 it is seen that the Young's modulus of pure PP, pure PLA, blend PP/PLA, polydopamine treated and PEDOT:PSS coated PP, PLA and PP/PLA is 76.98 MPa, $87.92 \mathrm{MPa}, 116.39 \mathrm{MPa}$; $230.70 \mathrm{MPa}$, 291.87 MPa, 309.29 MPa; 96.16 MPa, 172.11 MPa and 188.40 MPa respectively. The elongation at break of pure PP, pure PLA, blend PP/PLA, polydopamine treated and PEDOT:PSS coated PP, PLA and PP/PLA is $594.53 \%, 636.51 \%, 667.47 \% ; 42.30 \%, 76.89 \%, 121.35 \%$ and $227 \%, 264 \%, 315 \%$ respectively. So it is obvious that the polydopamine treatment and PEDOT:PSS coating have played vital a role for improving the mechanical properties of blend PP/PLA yarn.

However, it is clearly exhibited that introducing of PDA treatment and PEDOT:PSS coating illustrated a good improvement of mechanical properties of the treated and coated PP, PLA and $\mathrm{PP} / \mathrm{PLA}$ yarns due to the $-\mathrm{NH}_{2}$ functional group of dopamine and C-S bonds reaction happened among PDA treated thermoplastic yarns and PEDOT:PSS. This developed conductive yarns showed higher elongation at break\% compared to others development. For example, Luo et al. [67] developed PEDOT:PSS/PDMS blend conductive polymer films which showed elongation at break of about $82 \%$. Azizi et al. [37] also developed PP, PLA, and PP/PLA nanocomposite and the elongation at break of PP, PLA and PP/PLA are 210\%, 20\% and 25-150\% respectively. So this high stretchability feature from this present investigation was a good upshot for this study which may also be an intelligent aspects of these new yards to be applied for strain sensing application.

\subsection{Optical Microscopy Images Analysis}

Optical microscopy images were used to analyze the coating thickness of the PP, PLA and PP/PLA yarns at different stages to analyze the changes of coating thickness of PP, PLA and PP/PLA yarns after PDA treatment and PEDOT:PSS coating. Optical microscope images captured of several single yarns in a original state before PDA treatment, after PDA treatment and PEDOT:PSS coating show that there 
are significant changes in the thickness of boundary layers shown in Figure 8. It is mentioned that an image of the all yarns at 100 times magnification was captured in all stages.

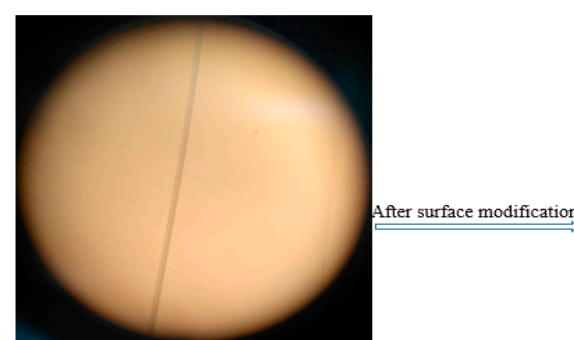

PP yarn

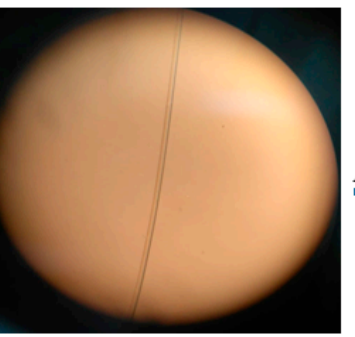

PLA yarn

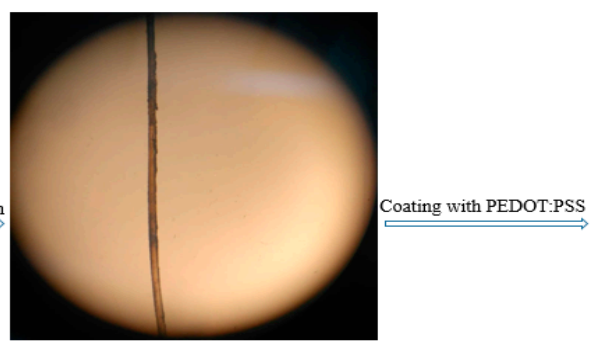

Modified PP yarn

(a)

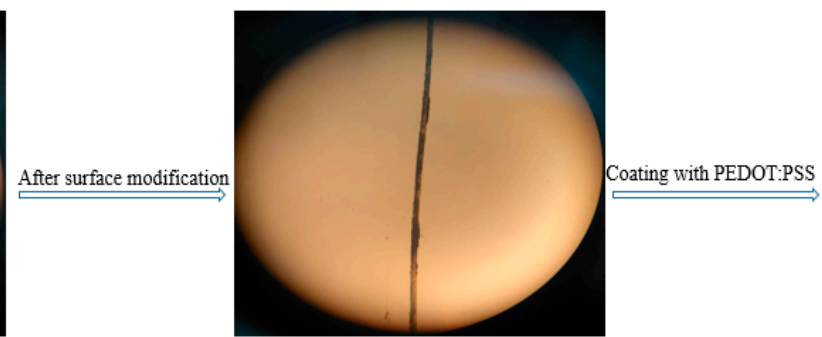

Modified PLA yarn

(b)

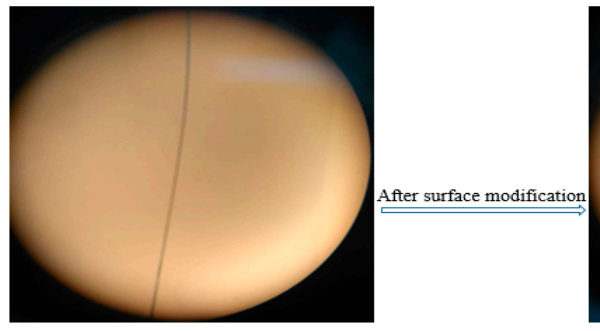

Composite (PP+PLA) yarn

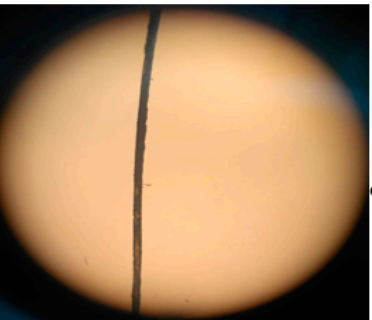

Modified composite yarn

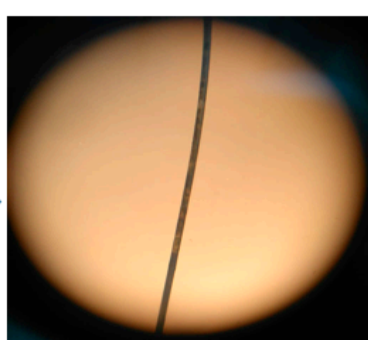

PEDOT:PSS coated PLA yarn

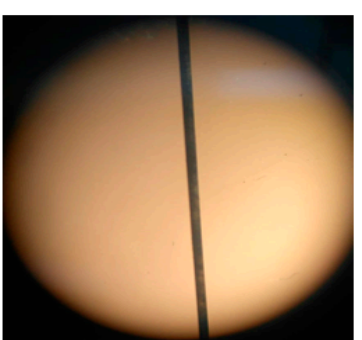

PEDOT:PSS coated PP yarn

(c)

Figure 8. Optical microscopic images of conductive (a) PP, (b) PLA and (c) blend PP/PLA yarn.

From Figure 8, it is seen that PDA treatment converts the white color of pure PP, PLA, and blend PP/PLA yarn into black which confirms the successful coating on thermoplastic yarns. So it can be assumed that PDA treatment has a great impact in the increased thickness of boundary layers of yarns and PEDOT:PSS pickup\%.

\subsection{Scanning Electron Microscope (SEM) Analysis}

The surface morphology of pure PP, pure PLA, blend PP/PLA, PDA treated, and PEDOT:PSS coated conductive PP, PLA, and PP/PLA yarns were also analyzed using SEM as shown in Figure 9, Figure 10, and Figure 11 respectively. A smooth surface morphology was observed without PDA coating while rough surface was observed in yarns which had been coated with PDA. This fact is evident from Figures 9a, 10a and 11a as a flat, smooth, and featureless surface of pure PP, pure PLA, and blend PP/PLA yarn can be observed. 


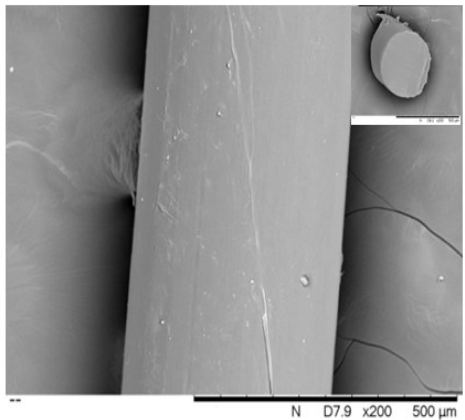

(a) Pure PP yarn

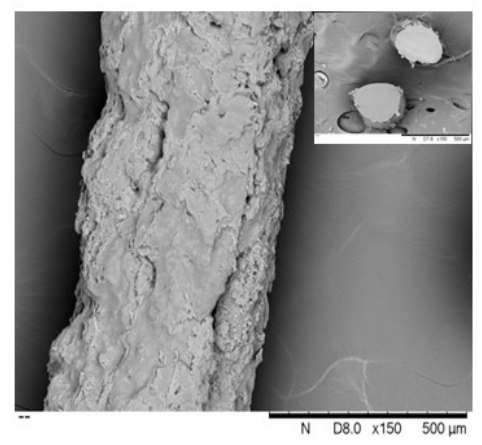

(b) PDA treated PP yarn

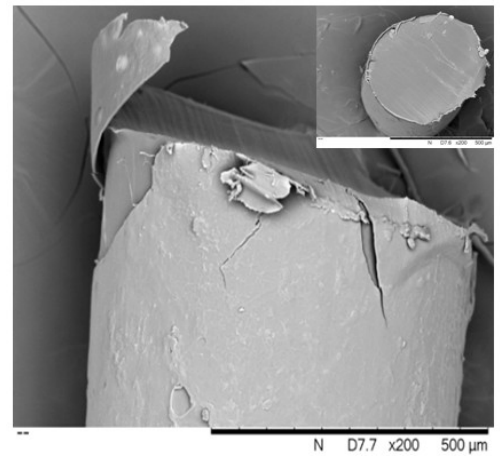

(c) PEDOT:PSS coated conductive PP yarn

Figure 9. SEM images (surface and cross-section) of PP yarn at various stages.

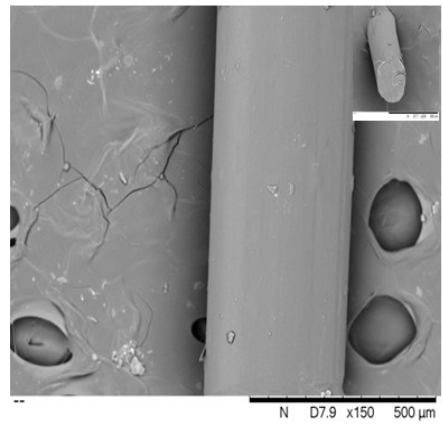

(a) Pure PLA yarn

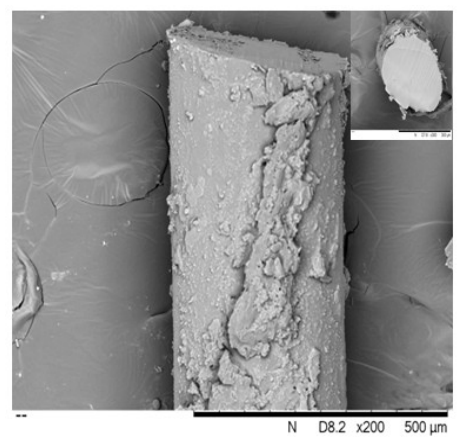

(b) PDA treated PLA yarn

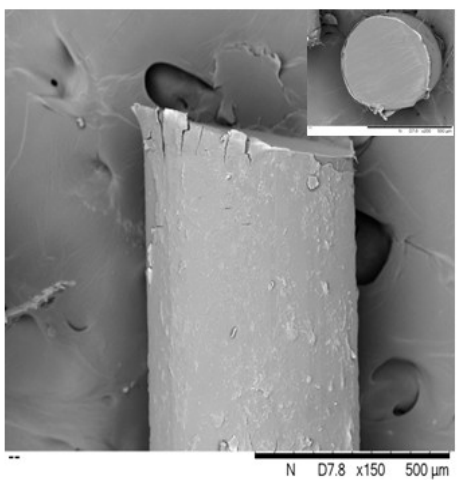

(c) PEDOT:PSS coated conductive PLA yarn

Figure 10. SEM images (surface and cross-section) of PLA yarn at various stages. 


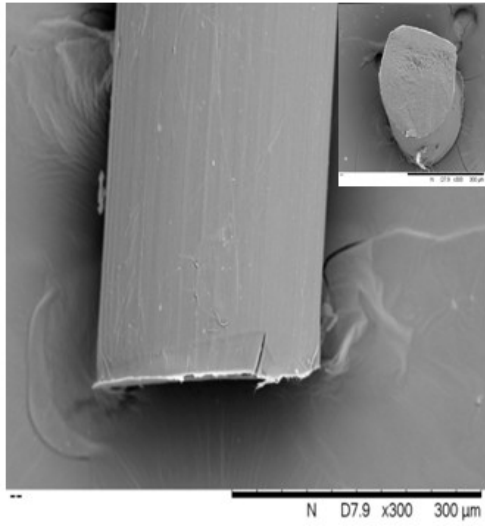

(a) Blend PP/PLA yarn

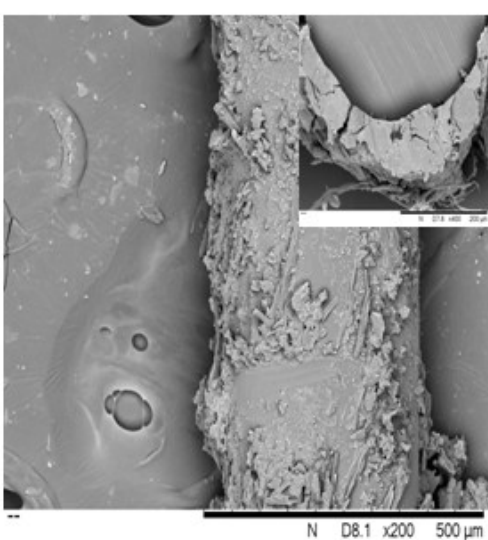

(b) PDA treated PP/PLA yarn

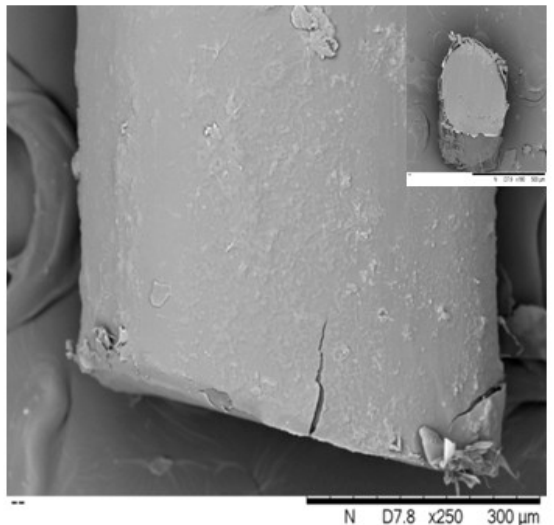

(c) PEDOT:PSS coated conductive PP/PLA yarn

Figure 11. SEM images (surface and cross-section) of PP/PLA yarn at various stages.

Figure $9 \mathrm{~b}$, Figure 10b, and Figure $11 \mathrm{~b}$ revealed densely rough, more intact features and granular morphology of PDA treated PP, PLA and PP/PLA yarns. After surface modification of thermoplastic yarns by PDA, the results showed that the thickness of the modified PP, PLA and PP/PLA coating were $3.96 \pm 1.45 \mu \mathrm{m}, 3.52 \pm 5.12 \mu \mathrm{m}$ and $6.71 \pm 3.9 \mu \mathrm{m}$ respectively. Though PDA coating layer was observed over surfaces of PP, PLA and PP/PLA surface but it was not smooth and cracks are visible. However, still this roughness created a hydrophilic base for further coating and increased the tensile strength of yarns.

Figure 9c, Figure 10c, and Figure 11c displayed the PEDOT:PSS coated conductive PP, PLA and PP/PLA yarns respectively. A clear wrapping of PEDOT:PSS can be seen in Figures 9c, 10c and 11c over the yarns of PP, PLA, and blend PP/PLA. After PEDOT:PSS coating, the thickness of coating layer of the coated PP, PLA and PP/PLA were $5.79 \pm 1.44 \mu \mathrm{m}, 5.62 \pm 1.0 \mu \mathrm{m}$ and $8.3 \pm 2.3 \mu \mathrm{m}$ respectively. This smooth morphology is critical for conductivity of materials as brittle surface can act as a barrier to flow of charges. The possible reason of achieving smooth surfaces of PEDOT:PSS coated thermoplastic yarns may be attributed to higher wettability, absorption and better linkage between the conductive polymer dispersion and the flexible substrates [68].

\subsection{Thermal Behavior Analysis}

\subsubsection{Thermo-Gravimetric Analysis (TGA)}

The thermal stability of pure PP, pure PLA, blend PP/PLA, PDA modified and PEDOT:PSS polymer coated conductive yarns were analyzed by thermos-gravimetric analysis under nitrogen atmosphere are shown in Figure 12a-c respectively. Here 5\% and 50\% mass loss occurring was 
investigated to maintain the accuracy of the thermal degradation temperatures characteristics. The two degradation temperatures $\mathrm{T}_{5 \%}$ and $\mathrm{T}_{50 \%}$ correspond to $5 \%$ and $50 \%$ mass loss of the samples respectively. The remaining ash $(\%)$ at $500{ }^{\circ} \mathrm{C}$ was also measured to determine the stability of various yarns. The mass loss $(5 \%, 50 \%)$ and the remaining ash (\%) were summarized in Table 4 .

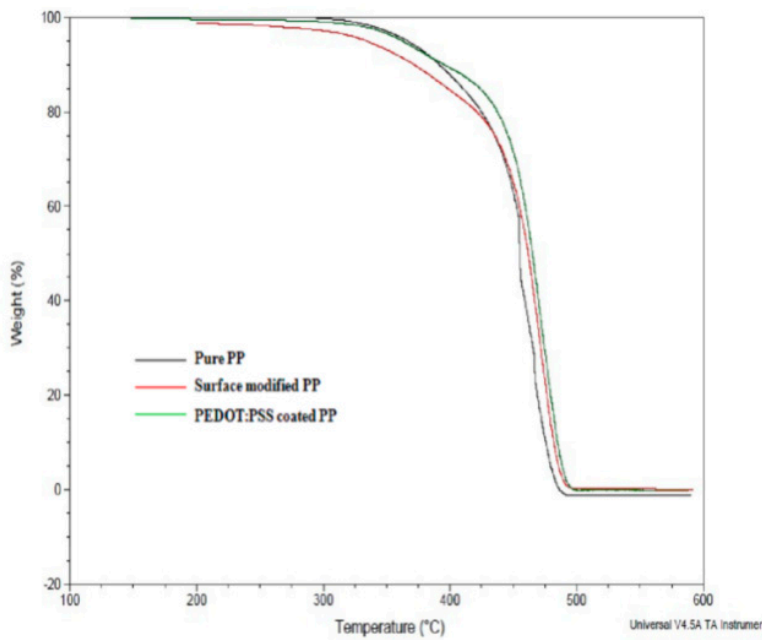

(a)

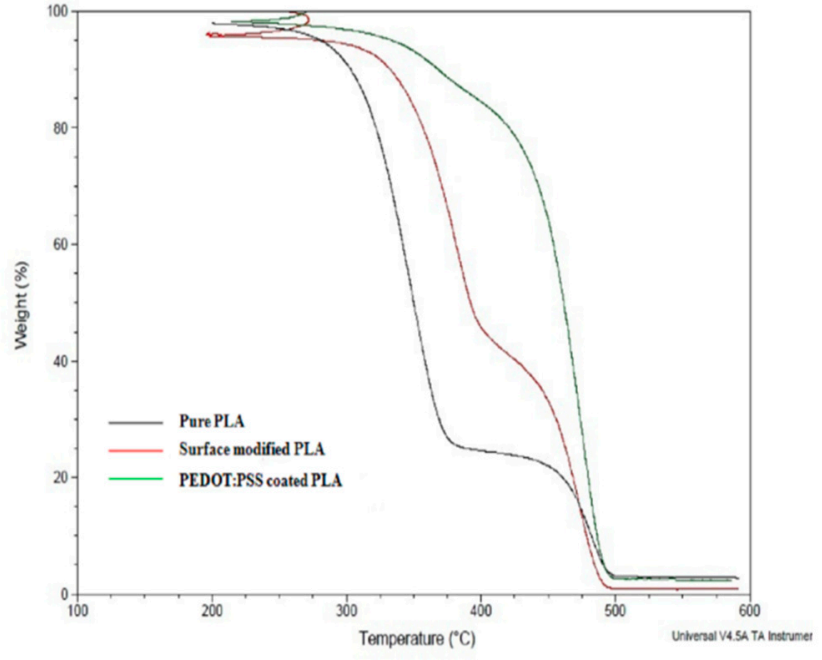

(b)

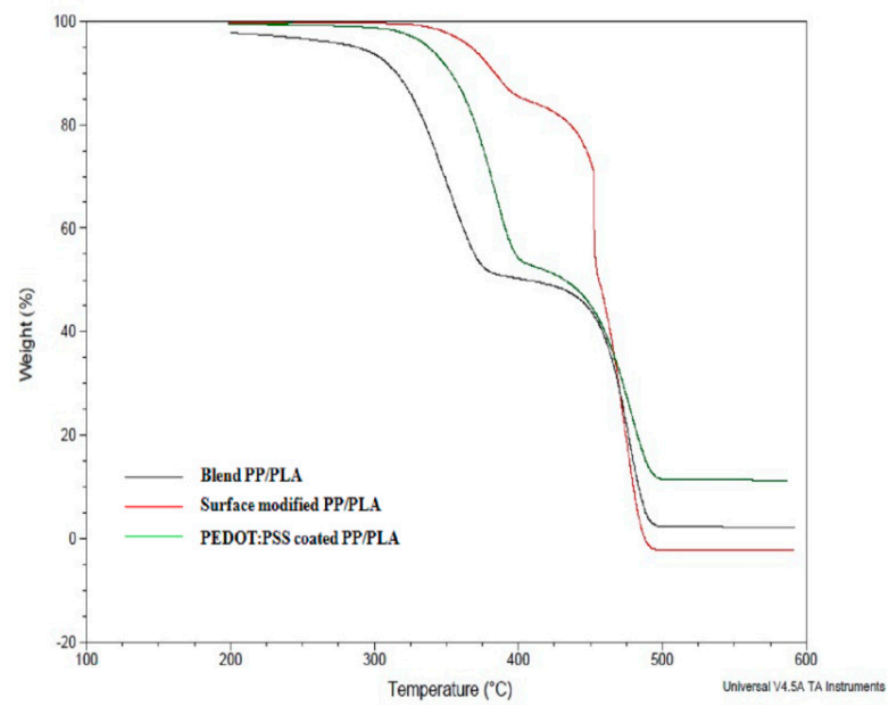

(c)

Figure 12. Thermogravimetric analysis (TGA) of PDA treated and PEDOT:PSS coated (a) PP, (b) PLA and (c) PP/PLA yarn. 
Table 4. TGA results of conductive PP, PLA and PP/PLA: $\mathrm{T}_{5 \%}, \mathrm{~T}_{50 \%}, \Delta \mathrm{T}$ and the remaining ash (\%) at $500{ }^{\circ} \mathrm{C}$.

\begin{tabular}{ccccc}
\hline Yarn Type & $\mathrm{T}_{\mathbf{5} \%}\left({ }^{\circ} \mathbf{C}\right)$ & $\mathrm{T}_{\mathbf{5 0} \%}\left({ }^{\circ} \mathbf{C}\right)$ & $\boldsymbol{\Delta} \mathbf{T}\left({ }^{\circ} \mathbf{C}\right)$ & Remaining Ash $(\%)$ at $\mathbf{5 0 0}{ }^{\circ} \mathbf{C}$ \\
\hline PP & 332 & 455 & - & 0.93 \\
Modified PP & 344 & 461 & 6 & 2.16 \\
PEDOT:PSS coated & 364 & 465 & 11 & 2.72 \\
PP & & & & 0.20 \\
PLA & 296 & 354 & - & 0.30 \\
Modified PLA & 307 & 372 & 18 & 0.39 \\
PEDOT:PSS coated & 333 & 393 & 39 & 1.16 \\
PLA & & & & 2.46 \\
PP/PLA & 315 & 386 & - & 4.84 \\
Modified PP/PLA & 317 & 412 & 26 & \\
PEDOT:PSS coated & 336 & 430 & 44 & \\
PP/PLA & & & & \\
\hline
\end{tabular}

$\Delta \mathrm{T}=$ temperature difference at $50 \%$ mass loss among the cross-linked samples and the neat polymers.

The thermal degradation curves of pure PP and pure PLA are also shown for comparison with modified and coated yarns. Figure $12 \mathrm{a}, \mathrm{b}$ illustrate that the pure PP, PLA, modified and coated yarns experience single stage mass loss. Remaining ash (\%) at $500{ }^{\circ} \mathrm{C}$ indicates that the introduction of PDA treatment and PEDOT:PSS coating improve the thermal stability of polymers with increase onset thermal degradation temperature and high molecular chain interaction with thermoplastic polymer.

From Figure 12c, it is seen that the thermo-grams of blend PP/PLA polymers reveal two-step degradation processes which indicate two mass loss. The first weight loss is due to the vanishing of the ester groups in the PLA polymer structure [37]. The second weight loss observed at $\sim 380{ }^{\circ} \mathrm{C}$ which indicates the decomposition of PP polymer. The addition of PLA in PP polymer to produce blend $\mathrm{PP} / \mathrm{PLA}$ decreases the initial degradation temperature to $315^{\circ} \mathrm{C}$ due to the incompatibility between PP and PLA polymers. However, the introduction of PDA and PEDOT:PSS coating increase the interfacial adhesion between PP and PLA. From remaining ash (\%) at $500{ }^{\circ} \mathrm{C}$, it is confirmed that the thermal stability of thermoplastic yarns has been enhanced by addition of PDA and PEDOT:PSS coating.

\subsubsection{Differential Scanning Calorimetry (DSC) Analysis}

To determine the thermal properties of pure PP, pure PLA, blend PP/PLA, PDA treated and PEDOT:PSS coated conductive yarns, DSC analysis was carried out and the thermo-grams are shown in Figure $13 a-c$ respectively. The glass transition temperature $\left(T_{g}\right)$ and melting temperature $\left(T_{m}\right)$ are summarized in Table 5. From Figure 13a, it is seen that no glass transition temperature is detected. The melting temperature (Tm) of PP yarn is detected at $130.92{ }^{\circ} \mathrm{C}$ [69]. After PDA treatment and PEDOT:PSS coating, melting point temperature $\left(\mathrm{T}_{\mathrm{m}}\right)$ of $\mathrm{PP}$ is revealed at $131.98{ }^{\circ} \mathrm{C}$ and $132.61{ }^{\circ} \mathrm{C}$ respectively. So it is noted that PDA treatment and PEDOT:PSS coating have increased the melting point $\left(T_{m}\right)$ of PP polymer. Moreover, from Figure $13 b$, it is seen that the $T_{g}$ of the pure PLA shows a hysteresis peak. The $\mathrm{T}_{\mathrm{g}}$ and $\mathrm{T}_{\mathrm{m}}$ of PLA are $56.44^{\circ} \mathrm{C}[64]$ and $131.55^{\circ} \mathrm{C}$ [70] respectively. 


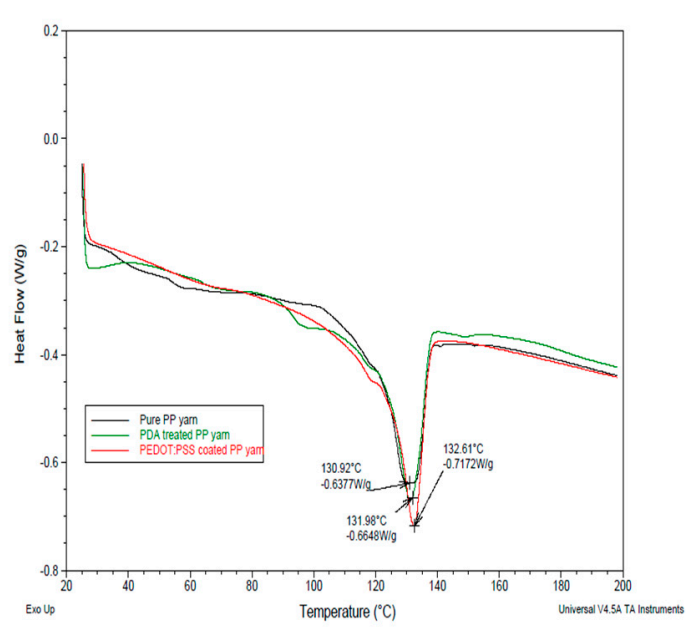

(a)

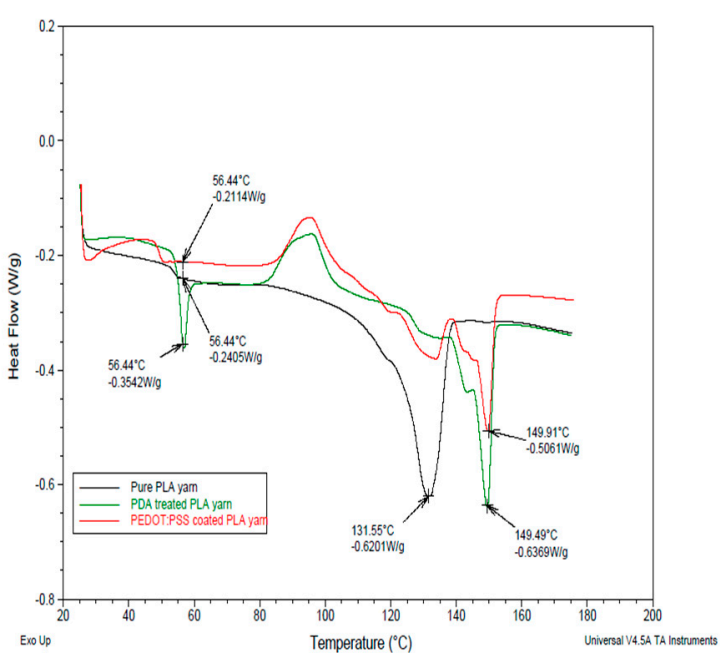

(b)

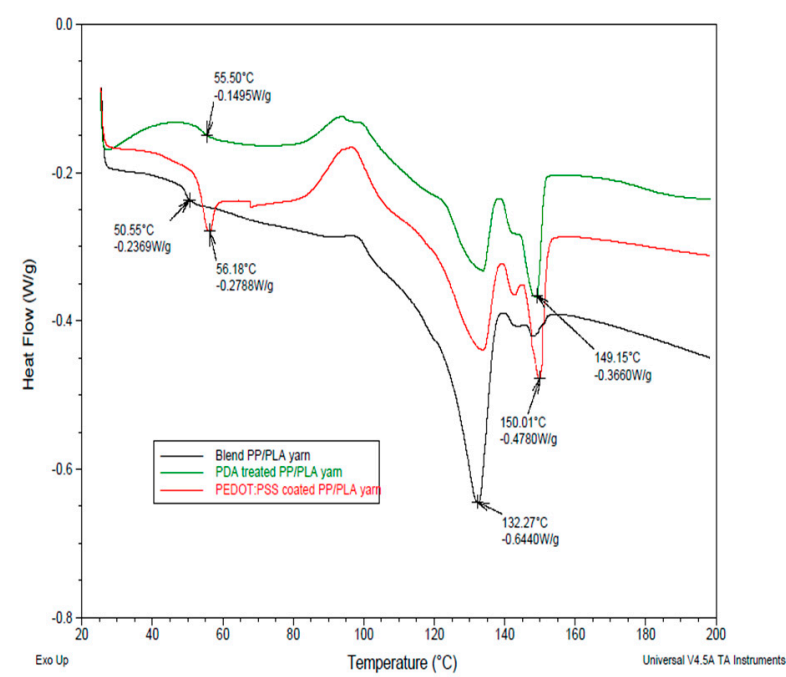

(c)

Figure 13. Differential scanning calorimetry (DSC) thermograms of PDA treated and PEDOT:PSS coated (a) PP, (b) PLA and (c) blend PP/PLA yarn.

Table 5. DSC results of glass transition temperature $\left(\mathrm{T}_{\mathrm{g}}\right)$ and melting point $\left(\mathrm{T}_{\mathrm{m}}\right)$ of PDA treated and PEDOT:PSS coated PP, PLA and PP/PLA yarns.

\begin{tabular}{ccc}
\hline Yarn Type & $\mathbf{T}_{\mathbf{g}}\left({ }^{\circ} \mathbf{C}\right)$ & $\mathbf{T}_{\mathbf{m}}\left({ }^{\circ} \mathbf{C}\right)$ \\
\hline PP & - & 130.92 \\
Modified PP & - & 131.98 \\
PEDOT:PSS coated PP & - & 132.61 \\
PLA & 56.44 & 131.55 \\
Modified PLA & 56.44 & 149.49 \\
PEDOT:PSS coated PLA & 56.44 & 149.91 \\
PP/PLA & 50.55 & 132.27 \\
Modified PP/PLA & 55.50 & 149.15 \\
PEDOT:PSS coated PP/PLA & 56.18 & 150.01 \\
\hline
\end{tabular}

The $\mathrm{T}_{\mathrm{g}}$ of the PLA remains same due to the reduction of the mobility of the amorphous character in the PLA polymer and the physical cross links with lower addition of PDA and PEDOT:PSS. 
A considerable increase is found in the $\mathrm{T}_{\mathrm{m}}$ of PLA after PDA treatment and coating due to the physical crosslink with PLA polymer. From Figure 13c, it is seen that the glass transition temperature of blend $\mathrm{PP} / \mathrm{PLA}$ polymer is $50.55^{\circ} \mathrm{C}$ [64]. After polydopamine treatment and PEDOT:PSS coating, the glass transition temperature of blend PP/PLA polymers have increased at $55.50{ }^{\circ} \mathrm{C}$ and $56.18{ }^{\circ} \mathrm{C}$ respectively.

Polymer blending of PLA with PP decrease the melting point of PP. The melting point of blend $\mathrm{PP} / \mathrm{PLA}$ is $132.27^{\circ} \mathrm{C}$. The melting points of polydopamine treated and PEDOT:PSS coated blend PP/PLA yarn are $149.15^{\circ} \mathrm{C}$ and $150.01^{\circ} \mathrm{C}$ respectively. So it is obvious that the addition of PEDOT:PSS coating increases the melting point of blend PP/PLA polymer because of the increased interfacial adhesion and interaction between the two polymer chains.

\subsection{Aging Effect on Electrical Conductivity under Different Processing Conditions}

For predicting and improving the shelf life of the developed conductive yarn, it is essential to analyze the degradation of the conducting material under end-use conditions during aging. Textile sensors will be used in several times. Consumers will wear this type of sensors and go outside. Then this sensors will be exposed to moisture, oxygen, and sunlight. So the developed conductive yarns were stored in a real conditioning room maintaining the parameters (temp. $20{ }^{\circ} \mathrm{C}$ and R.H. $65 \pm 4 \%$ ) for five weeks to analyze and measure the effect of oxygen, sunlight, and moisture content on the electric conductivity of conductive yarns. Table 6 represents the aging effect on electrical resistance of PEDOT:PSS coated conductive PP, PLA and PP/PLA yarn.

Table 6. Aging effect of PEDOT:PSS coated conductive yarns.

\begin{tabular}{|c|c|c|c|c|c|c|c|c|c|}
\hline \multirow{3}{*}{$\begin{array}{l}\text { Conductive } \\
\text { Yarn Type }\end{array}$} & \multirow{3}{*}{$\begin{array}{l}\text { Aging } \\
\text { Duration } \\
\text { (Week) }\end{array}$} & \multicolumn{8}{|c|}{ Electrical Resistance (K $\Omega$ ) } \\
\hline & & \multicolumn{4}{|c|}{ For 1st Coating } & \multicolumn{4}{|c|}{ For 2nd Coating } \\
\hline & & Mean & SD & $\begin{array}{c}\text { Increased } \\
\text { Electrical } \\
\text { Resistance } \\
\text { Every } \\
\text { Week (\%) }\end{array}$ & $\begin{array}{c}\text { Total Increased } \\
\text { Electrical } \\
\text { Resistance }(\%) \\
\text { from Week } \\
\text { 0-Week } 5(\%)\end{array}$ & Mean & SD & $\begin{array}{c}\text { Increased } \\
\text { Electrical } \\
\text { Resistance (\%) }\end{array}$ & $\begin{array}{c}\text { Total Increased } \\
\text { Electrical } \\
\text { Resistance (\%) } \\
\text { from Week } \\
\text { 0-Week } 5(\%) \\
\end{array}$ \\
\hline \multirow{6}{*}{ PP } & 0 & 131.00 & 3.41 & - & \multirow{6}{*}{23.43} & 43.00 & 2.08 & - & \multirow{6}{*}{20.98} \\
\hline & 1 & 143.07 & 1.63 & 9.21 & & 44.70 & 0.46 & 3.95 & \\
\hline & 2 & 149.67 & 0.57 & 4.61 & & 46.93 & 0.57 & 4.99 & \\
\hline & 3 & 154.70 & 2.03 & 3.36 & & 48.73 & 0.75 & 3.84 & \\
\hline & 4 & 159.30 & 1.91 & 2.97 & & 51.37 & 1.32 & 5.42 & \\
\hline & 5 & 164.53 & 0.83 & 3.28 & & 52.80 & 0.30 & 2.78 & \\
\hline \multirow{6}{*}{ PLA } & 0 & 223.00 & 7.76 & - & \multirow{6}{*}{26.85} & 122.00 & 5.47 & - & \multirow{6}{*}{23.00} \\
\hline & 1 & 251.10 & 1.11 & 12.60 & & 134.13 & 1.05 & 9.94 & \\
\hline & 2 & 262.40 & 2.80 & 4.50 & & 139.40 & 1.20 & 3.92 & \\
\hline & 3 & 269.10 & 1.74 & 2.55 & & 143.33 & 0.86 & 2.82 & \\
\hline & 4 & 279.10 & 2.16 & 3.72 & & 148.50 & 0.86 & 3.61 & \\
\hline & 5 & 288.80 & 2.35 & 3.48 & & 152.53 & 0.83 & 2.71 & \\
\hline \multirow{6}{*}{ PP/PLA } & 0 & 181.00 & 3.63 & - & \multirow{6}{*}{25.45} & 66.00 & 1.23 & - & \multirow{6}{*}{21.96} \\
\hline & 1 & 199.50 & 0.79 & 10.22 & & 73.43 & 0.65 & 11.26 & \\
\hline & 2 & 210.50 & 1.12 & 5.51 & & 75.67 & 0.57 & 3.05 & \\
\hline & 3 & 215.33 & 0.96 & 2.29 & & 78.50 & 0.87 & 3.74 & \\
\hline & 4 & 223.40 & 0.79 & 3.75 & & 80.80 & 0.36 & 2.93 & \\
\hline & 5 & 231.63 & 0.42 & 3.68 & & 81.63 & 0.87 & 1.03 & \\
\hline
\end{tabular}

Here the gain of electrical resistance on aging was evaluated in every week. By calculating this total increased electrical resistance (\%), the effect of atmospheric storage was analyzed. Considering the dip coating cycle 1 and 2, electrical resistance of conductive PP, PLA and PP/PLA yarn increased by $\sim 23.43 \%, \sim 20.98 \% ; \sim 26.85 \%, \sim 23 \%$ and $\sim 25.45 \%, \sim 21.96 \%$ respectively in five weeks due to aging under storage conditions. Considering the increase of electric resistance, it is confirmed that aging has enormous effect on the shelf life of these conductive materials. The reason for increase in the electrical resistance of PEDOT:PSS coated conductive yarns may be the oxidative degradation by oxygen and the degradation of the conductive material by the atmospheric moisture. 


\subsection{Electrical Conductivity after Rinsing}

Conductive yarns must be sufficiently robust to be suitable for daily use particularly in respect of bending, abrasion, and cleaning. Wash durable conductive yarns production is a great technical challenge for repeat use. Conductive tracks typically cannot survive machine washing due to the mechanical stresses, reaction between detergent and water. The cleaning stability and washing performance of both PEDOT:PSS coated conductive yarns were analyzed. Figure 14 shows the relationship between electrical conductivity $(\mathrm{S} / \mathrm{cm})$ and rinsing cycles of PEDOT:PSS coated PP, PLA, and PP/PLA yarns after five rinsing cycles. Electrical conductivity of the conductive yarns was considerably decreased every after rinsing cycle.

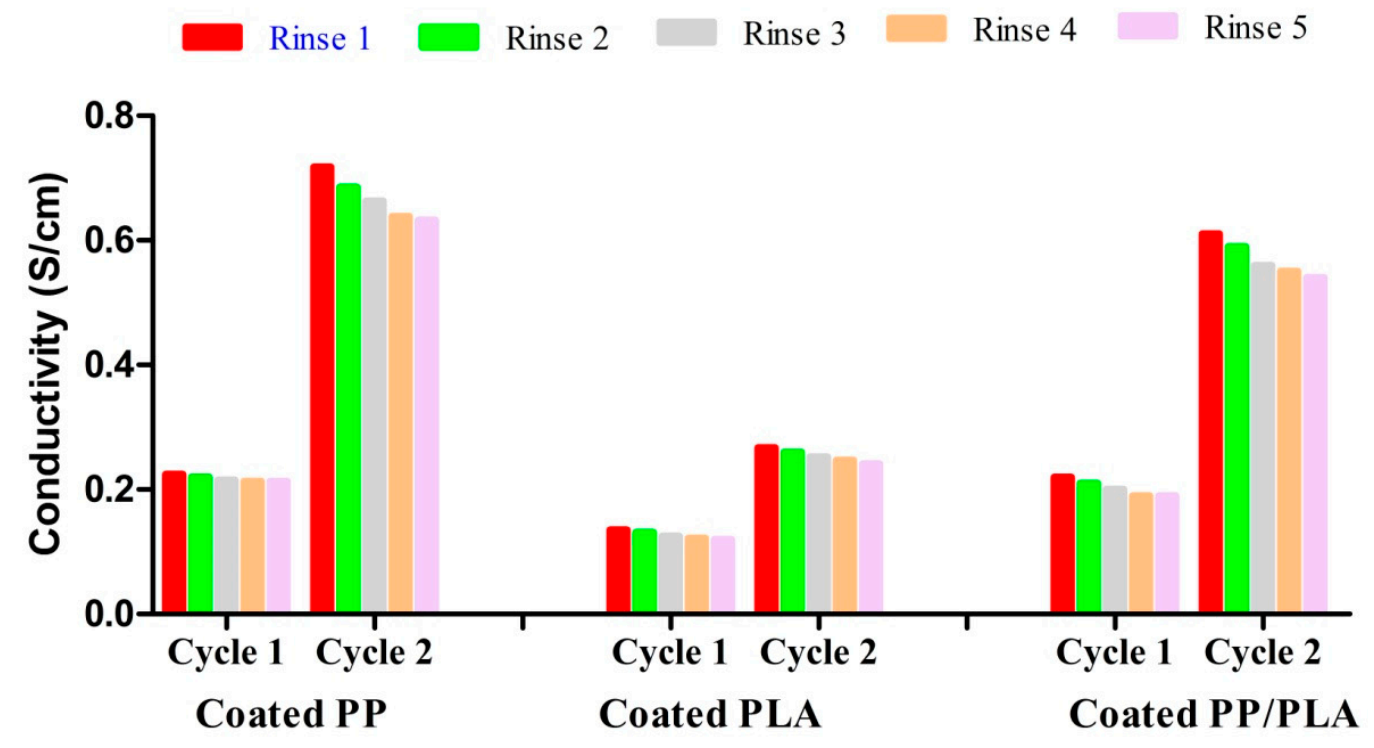

Figure 14. Conductivity (S/cm) of PEDOT:PSS coated PP, PLA and PP/PLA yarns after rinsing.

Before rinsing the conductivity for dip coating cycle 1 and cycle 2 of conductive PP yarn was $0.25 \mathrm{~S} / \mathrm{cm}$ and $0.75 \mathrm{~S} / \mathrm{cm}$ respectively. After 5 th rinsing of conductive PP yarn, the conductivity for dip coating cycle 1 and cycle 2 is $0.213 \mathrm{~S} / \mathrm{cm}$ and $0.632 \mathrm{~S} / \mathrm{cm}$ respectively. The decreased conductivity of PP yarn for cycle 1 and cycle 2 is $14.8 \%$ and $15.73 \%$ respectively. Similarly before rinsing the conductivity for dip coating cycle 1 and cycle 2 of conductive PLA yarn was $0.17 \mathrm{~S} / \mathrm{cm}$ and $0.36 \mathrm{~S} / \mathrm{cm}$ respectively. After 5th rinsing of conductive PLA yarn, the conductivity for dip coating cycle 1 and cycle 2 is $0.12 \mathrm{~S} / \mathrm{cm}$ and $0.241 \mathrm{~S} / \mathrm{cm}$, respectively. Therefore the decreased conductivity of PLA yarn for dip coating cycle 1 and cycle 2 is $29.41 \%$ and $33.06 \%$ respectively. Before rinsing the conductivity for dip coating cycle 1 and cycle 2 of conductive composite (PP/PLA)yarn was $0.24 \mathrm{~S} / \mathrm{cm}$ and $0.67 \mathrm{~S} / \mathrm{cm}$ respectively. After 5th rinsing of conductive PP/PLA yarn, the conductivity for dip coating cycle 1 and cycle 2 of conductive PP/PLA yarn is $0.19 \mathrm{~S} / \mathrm{cm}$ and $0.54 \mathrm{~S} / \mathrm{cm}$ respectively. The decreased conductivity of blend PP/PLA yarn for dip coating cycle 1 and cycle 2 is $20.83 \%$ and $19.40 \%$, respectively. This decreased electrical conductivity could be due to the removal of excess unfix PEDOT:PSS on the yarn surface. Here conductive PP yarn showed better cleaning stability compared to conductive PLA and composite PP/PLA yarn.

\section{Conclusions}

A new class of smart interactive textiles ( $i$-textiles) is being designed to develop new strategies toward smart materials for innovative applications in the various fields including public safety, healthcare, artificial muscles, military, strain sensing, space exploration, stretchable displays, sports, and consumer fitness. This manuscript detailing of it study results has demonstrated to construct highly stretchable, cost effective, durable, and environmentally friendly melt spun thermoplastic conductive 
yarns with excellent thermal and mechanical properties. Here we have introduced mussel-inspired polydodapine (PDA) treatment to modify the surface of the melt spun thermoplastic yarns. This PDA treatment acts not only as a coupling or bonding agent but also as plasticizer. This dual characteristics illustrate significant improvement of surface properties of the thermoplastic yarns. These PDA treated thermoplastic yarns consisting of PP, PLA, and PP/PLA that were effectively coated with PEDOT:PSS toward increasing the efficacy of wearable textile sensors. Mechanically the conductive PP, PLA, and PP/PLA yarns were highly stretchable and flexible. These highly stretchable and flexible conductive yarns can be used for producing conductive textiles by knitting and also can be integrated into any textile substrates/fabrics by sewing. The usage of these conductive yarns might be applied to analyze sporting performance and heart beat of a sportsman, tiny joint movement of human body, the health record of patients, speaking, swallowing and breathing.

Author Contributions: Conceptualization, G.M.N.I.; methodology, G.M.N.I.; software, G.M.N.I.; validation, G.M.N.I.; formal analysis, G.M.N.I.; investigation, G.M.N.I. and M.Q.; resources, G.M.N.I.; M.A.A. and S.C.; data curation, G.M.N.I. and M.Q.; writing-original draft preparation, G.M.N.I.; writing-review and editing, all authors; visualization, G.M.N.I.; supervision, M.A.A. and S.C.; project administration, M.A.A. and S.C. All authors have read and agreed to the published version of the manuscript.

Funding: This research received no external funding.

Acknowledgments: The authors would like to acknowledge the financial support from Home Science Alumnae/Todhunter/Carpenter Scholarship, University of Otago, Dunedin, New Zealand.

Conflicts of Interest: The authors declare no conflict of interest.

\section{References}

1. Islam, G.M.N.; Ali, A.; Collie, S. Textile sensors for wearable applications: A comprehensive review. Cellulose 2020, 27, 6103-6131. [CrossRef]

2. Cheng, Y.; Zhu, T.; Li, S.; Huang, J.; Mao, J.; Yang, H.; Gao, S.; Chen, Z.; Lai, Y. A novel strategy for fabricating robust superhydrophobic fabrics by environmentally-friendly enzyme etching. Chem. Eng. J. 2019, 355, 290-298. [CrossRef]

3. Zhang, Y.; Lin, Z.; Huang, X.; You, X.; Ye, J.; Wu, H. A Large area, stretchable, textile based tactile sensor. Adv. Mater. Technol. 2020, 5, 1901060-1901069. [CrossRef]

4. Fan, X.; Zhan, Y.; Xu, H.; Hou, Z.; Liu, X.; Riedel, R. Highly flexible, light-weight and mechanically enhanced (Mo2C/PyC)f fabrics for efficient electromagnetic interference shielding. Compos. Part A Appl. Sci. Manuf. 2020, 136, 105955-105963. [CrossRef]

5. Islam, G.M.N.; Ke, G. Ultrasonic effects on the kinetics and thermodynamics of dyeing wool fiber with reactive dye. Fibers Polym. 2020, 21, 1071-1077. [CrossRef]

6. $\mathrm{Xu}, \mathrm{T}$; Zhang, Z.; Qu, L. Graphene based fibers: Recent advances in preparation and application. Adv. Mater. 2020, 32, 1901979-1901994. [CrossRef] [PubMed]

7. Cui, Y.; Zhang, M.; Li, J.; Luo, H.; Zhang, X.; Fu, Z. WSMS: Wearable stress monitoring system based on IoT multi-sensor platform for living sheep transportation. Electronics 2019, 8, 441. [CrossRef]

8. Kayser, L.V.; Lipomi, D.J. Stretchable conductive polymers and composites based on PEDOT and PEDOT:PSS. Adv. Mater. 2019, 31, 1806133-1806145. [CrossRef]

9. Mohan Bhasney, S.; Kumar, A.; Katiyar, V. Microcrystalline cellulose, polylactic acid and polypropylene biocomposites and its morphological, mechanical, thermal and rheological properties. Compos. Part B Eng. 2020, 184, 107717-107731. [CrossRef]

10. Schwarz, P.A.; Obermann, M.; Weber, M.; Ehrmann, A. Smarten up garments through knitting. In Proceedings of the 48th Conference of the International Federation of Knitting Technologists (IFKT), IOP Conference Series, Moenchengladbach, Germany, 8-11 June 2016; pp. 1-8.

11. Kong, X.; Zhu, C.; Lv, J.; Zhang, J.; Feng, J. Robust fluorine-free superhydrophobic coating on polyester fabrics by spraying commercial adhesive and hydrophobic fumed $\mathrm{SiO}_{2}$ nanoparticles. Prog. Org. Coat. 2020, 138, 105342-105351. [CrossRef]

12. Sadi, M.S.; Pan, J.; Xu, A.; Cheng, D.; Cai, G.; Wang, X. Direct dip-coating of carbon nanotubes onto polydopamine-templated cotton fabrics for wearable applications. Cellulose 2019, 26, 7569-7579. [CrossRef] 
13. Baribina, N.; Baltina, I.; Oks, A. Application of additional coating for conductive yarns protection against washing. Key Eng. Mater. 2018, 762, 396-401. [CrossRef]

14. Zhang, C.; Zhou, G.; Rao, W.; Fan, L.; Xu, W.; Xu, J. A simple method of fabricating nickel-coated cotton fabrics for wearable strain sensor. Cellulose 2018, 25, 4859-4870. [CrossRef]

15. Li, W.; Xu, F.; Liu, W.; Gao, Y.; Zhang, K.; Zhang, X.; Qiu, Y. Flexible strain sensor based on aerogel spun carbon nanotube yarn with a core-sheath structure. Compos. Part A Appl. Sci. Manuf. 2018, 108, 107-113. [CrossRef]

16. Memarian, F.; Rahmani, S.; Yousefzadeh, M.; Latifi, M. Wearable Technologies in Sportswear. In Materials in Sports Equipment; Elsevier: Amsterdam, The Netherlands, 2019; pp. 123-160. [CrossRef]

17. Karim, N.; Afroj, S.; Malandraki, A.; Butterworth, S.; Beach, C.; Rigout, M.; Novoselov, K.S.; Casson, A.J.; Yeates, S.G. All inkjet-printed graphene based conductive patterns for wearable e-textile applications. J. Mater. Chem. C 2017, 5, 11640-11648. [CrossRef]

18. Aslam, S.; Bokhari, T.H.; Anwar, T.; Khan, U.; Nairan, A.; Khan, K. Graphene oxide coated graphene foam based chemical sensor. Mater. Lett. 2019, 235, 66-70. [CrossRef]

19. Wu, B.; Xu, P.; Yang, W.; Hoch, M.; Dong, W.; Chen, M.; Bai, H.; Ma, P. Super toughened heat resistant poly(lactic acid) alloys by tailoring the phase morphology and the crystallization behaviors. J. Polym. Sci. 2020, 58, 500-509. [CrossRef]

20. Bouchart, F.; Vidal, O.; Lacroix, J.M.; Spriet, C.; Chamary, S.; Brutel, A.; Hornez, J.C. 3D printed bioceramic for phage therapy against bone nosocomial infections. Mater. Sci. Eng. C Mater. Biol. Appl. 2020, 111, 110840-110852. [CrossRef]

21. Chen, W.; Xu, Y.; Li, Y.; Jia, L.; Mo, X.; Jiang, G.; Zhou, G. 3D printing electrospinning fiber-reinforced decellularized extracellular matrix for cartilage regeneration. Chem. Eng. J. 2020, 382, 122986-122995. [CrossRef]

22. Ueda, M.; Kishimoto, S.; Yamawaki, M.; Matsuzaki, R.; Todoroki, A.; Hirano, Y.; Le Duigou, A. 3D compaction printing of a continuous carbon fiber reinforced thermoplastic. Compos. Part A Appl. Sci. Manuf. 2020, 137, 105985-105993. [CrossRef]

23. Sarker, F.; Potluri, P.; Afroj, S.; Koncherry, V.; Novoselov, K.S.; Karim, N. Ultrahigh performance of nanoengineered graphene based natural jute fiber composites. ACS Appl. Mater. Interfaces 2019, 11, 21166-21176. [CrossRef]

24. Afroj, S.; Tan, S.; Abdelkader, A.M.; Novoselov, K.S.; Karim, N. Highly conductive, scalable and machine washable graphene-based E-textiles for multifunctional wearable electronic applications. Adv. Funct. Mater. 2020, 30, 2000293-2000302. [CrossRef]

25. Afroj, S.; Karim, N.; Wang, Z.; Tan, S.; He, P.; Holwill, M.; Ghazaryan, D.; Fernando, A.; Novoselov, K.S. Engineering graphene flakes for wearable textile sensors via highly scalable and ultrafast yarn dyeing technique. ACS Nano 2019, 13, 3847-3857. [CrossRef] [PubMed]

26. Su, S.; Kang, P.M. Systemic review of biodegradable nanomaterials in nanomedicine. Nanomaterials 2020, 10, 656. [CrossRef] [PubMed]

27. Liu, H.; Jian, R.; Chen, H.; Tian, X.; Sun, C.; Zhu, J.; Yang, Z.; Sun, J.; Wang, C. Application of biodegradable and biocompatible nanocomposites in electronics: Current status and future directions. Nanomaterials 2019, 9, 950. [CrossRef]

28. Sonseca, A.; Madani, S.; Muñoz Bonilla, A.; Fernández García, M.; Peponi, L.; Leonés, A.; Rodríguez, G.; Echeverría, C.; López, D. Biodegradable and antimicrobial PLA-OLA blends containing chitosan-mediated silver nanoparticles with shape memory properties for potential medical applications. Nanomaterials 2020, 10, 1065. [CrossRef]

29. Huang, T.; Kwan, I.; Li, K.D.; Ek, M. Effect of cellulose oxalate as cellulosic reinforcement in ternary composites of polypropylene/maleated polypropylene/cellulose. Compos. Part A Appl. Sci. Manuf. 2020, 134, 105894-105904. [CrossRef]

30. Mandal, D.K.; Bhunia, H.; Bajpai, P.K. Thermal degradation kinetics of PP/PLA nanocomposite blends. J. Thermoplast. Compos. Mater. 2019, 32, 1714-1730. [CrossRef]

31. Zakaria, M.; Nakane, K. Fabrication of polypropylene nanofibers from polypropylene/polyvinyl butyral blend films using laser assisted melt-electrospinning. Polym. Eng. Sci. 2020, 60, 362-370. [CrossRef] 
32. Zengwen, C.; Lu, Z.; Pan, H.; Bian, J.; Han, L.; Zhang, H.; Dong, L.; Yang, Y. Structuring poly (lactic acid) film with excellent tensile toughness through extrusion blow molding. Polymer 2020, 187, 122091-122098. [CrossRef]

33. Muthuraj, R.; Misra, M.; Mohanty, A.K. Biodegradable compatibilized polymer blends for packaging applications: A literature review. J. Appl. Polym. Sci. 2018, 135, 45726-45760. [CrossRef]

34. Cui, X.; Honda, T.; Asoh, T.A.; Uyama, H. Cellulose modified by citric acid reinforced polypropylene resin as fillers. Carbohydr. Polym. 2020, 230, 115662-115670. [CrossRef] [PubMed]

35. Pivsa Art, S.; Kord Sa Ard, J.; Pivsa Art, W.; Wongpajan, R.; O-Charoen, N.; Pavasupree, S.; Hamada, H. Effect of Compatibilizer on PLA/PP Blend for Injection Molding. Energy Procedia 2016, 89, 353-360. [CrossRef]

36. Mohamad, I.N.; Rohani, R.; Masdar, M.S.; Nor, M.; Tusirin, M.; Jamaliah, M.J. Permeation properties of polymeric membranes for biohydrogen purification. Int. J. Hydrogen Energy 2016, 41, 4474-4488. [CrossRef]

37. Azizi, S.; Azizi, M.; Sabetzadeh, M. The role of multiwalled carbon nanotubes in the mechanical, thermal, rheological and electrical properties of PP/PLA/MWCNTs nanocomposites. J. Compos. Sci. 2019, 3, 64. [CrossRef]

38. Lynge, M.E.; van der Westen, R.; Postma, A.; Städler, B. Polydopamine-A nature-inspired polymer coating for biomedical science. Nanoscale 2011, 3, 4916-4928. [CrossRef]

39. El Yakhlifi, S.; Ball, V. Polydopamine as a stable and functional nanomaterial. Colloids Surf. B Biointerfaces 2020, 186, 110719-110726. [CrossRef]

40. Hu, H.; Yu, B.; Ye, Q.; Gu, Y.; Zhou, F. Modification of carbon nanotubes with a nanothin polydopamine layer and polydimethylamino-ethyl methacrylate brushes. Carbon 2010, 48, 2347-2353. [CrossRef]

41. Cherenack, K.; Zysset, C.; Kinkeldei, T.; Münzenrieder, N.; Tröster, G. Woven electronic fibers with sensing and display functions for smart textiles. Adv. Mater. 2010, 22, 5178-5182. [CrossRef]

42. Bontapalle, S.; Varughese, S. Understanding the mechanism of ageing and a method to improve the ageing resistance of conducting PEDOT:PSS films. Polym. Degrad. Stab. 2020, 171, 1-11. [CrossRef]

43. Lund, A.; van der Velden, N.M.; Persson, N.-K.; Hamedi, M.M.; Müller, C. Electrically conducting fibres for e-textiles: An open playground for conjugated polymers and carbon nanomaterials. Mater. Sci. Eng. R Rep. 2018, 126, 1-29. [CrossRef]

44. Kim, S.M.; Kim, C.H.; Kim, Y.; Kim, N.; Lee, W.J.; Lee, E.H.; Kim, D.; Park, S.; Lee, K.; Rivnay, J.; et al. Influence of PEDOT:PSS crystallinity and composition on electrochemical transistor performance and long-term stability. Nat. Commun. 2018, 9, 3858-3866. [CrossRef] [PubMed]

45. Yin, F.; Ye, D.; Zhu, C.; Qiu, L.; Huang, Y. Stretchable, highly durable ternary nanocomposite strain sensor for structural health monitoring of flexible aircraft. Sensors 2017, 17, 2677. [CrossRef] [PubMed]

46. Wang, J.; Wang, J.; Kong, Z.; Lv, K.; Teng, C.; Zhu, Y. Conducting polymer based materials for electrochemical energy conversion and storage. Adv. Mater. 2017, 29, 1703044-1703054. [CrossRef]

47. Naveen, M.H.; Gurudatt, N.G.; Shim, Y.-B. Applications of conducting polymer composites to electrochemical sensors: A review. Appl. Mater. Today 2017, 9, 419-433. [CrossRef]

48. Le, T.H.; Kim, Y.; Yoon, H. Electrical and electrochemical properties of conducting polymers. Polymers 2017, 9, 150. [CrossRef]

49. Eom, J.; Jaisutti, R.; Lee, H.; Lee, W.; Heo, J.S.; Lee, J.Y.; Park, S.K.; Kim, Y.H. Highly sensitive textile strain sensors and wireless user interface devices using all polymeric conducting fibers. ACS Appl. Mater. Interfaces 2017, 9, 10190-10197. [CrossRef]

50. Allison, L.; Hoxie, S.; Andrew, T.L. Towards seamlessly-integrated textile electronics: Methods to coat fabrics and fibers with conducting polymers for electronic applications. Chem. Commun. 2017, 53, 7182-7193. [CrossRef]

51. Gao, Q.; Wang, M.; Kang, X.; Zhu, C.; Ge, M. Continuous wet-spinning of flexible and water-stable conductive PEDOT: PSS/PVA composite fibers for wearable sensors. Compos. Commun. 2020, 17, 134-140. [CrossRef]

52. Reid, D.O.; Smith, R.E.; Garcia Torres, J.; Watts, J.F.; Crean, C. Solvent Treatment of wet-spun PEDOT: PSS fibers for fiber-based wearable $\mathrm{pH}$ sensing. Sensors 2019, 19, 4213. [CrossRef]

53. Shan, Y.; Xu, C.; Zhang, H.; Chen, H.; Bilal, M.; Niu, S.; Cao, L.; Huang, Q. Polydopamine modified metal-organic frameworks, NH2-Fe-MIL-101, as $\mathrm{pH}$-sensitive nanocarriers for controlled pesticide release. Nanomaterials 2020, 10, 2000. [CrossRef] [PubMed] 
54. Moraes, M.R.; Alves, A.C.; Toptan, F.; Martins, M.S.; Vieira, E.M.F.; Paleo, A.J.; Souto, A.P.; Santos, W.L.F.; Esteves, M.F.; Zille, A. Glycerol/PEDOT:PSS coated woven fabric as a flexible heating element on textiles. J. Mater. Chem. C 2017, 5, 3807-3822. [CrossRef]

55. Cai, G.; Yang, M.; Xu, Z.; Liu, J.; Tang, B.; Wang, X. Flexible and wearable strain sensing fabrics. Chem. Eng. J. 2017, 325, 396-403. [CrossRef]

56. Chen, H.; Lv, L.; Zhang, J.; Zhang, S.; Xu, P.; Li, C.; Zhang, Z.; Li, Y.; Xu, Y.; Wang, J. Enhanced stretchable and sensitive strain sensor via controlled strain distribution. Nanomaterials 2020, 10, 218. [CrossRef] [PubMed]

57. Chen, X.; An, J.; Cai, G.; Zhang, J.; Chen, W.; Dong, X.; Zhu, L.; Tang, B.; Wang, J.; Wang, X. Environmentally friendly flexible strain sensor from waste cotton fabrics and natural rubber latex. Polymers 2019, 11, 404. [CrossRef]

58. Tadesse, M.G.; Mengistie, D.A.; Chen, Y.; Wang, L.; Loghin, C.; Nierstrasz, V. Electrically conductive highly elastic polyamide/lycra fabric treated with PEDOT:PSS and polyurethane. J. Mater. Sci. 2019, 54, 9591-9602. [CrossRef]

59. Strååt, M.; Toll, S.; Boldizar, A.; Rigdahl, M.; Hagström, B. Melt spinning of conducting polymeric composites containing carbonaceous fillers. J. Appl. Polym. Sci. 2011, 119, 3264-3272. [CrossRef]

60. Soroudi, A.; Skrifvars, M. Melt blending of carbon nanotubes/polyaniline/polypropylene compounds and their melt spinning to conductive fibres. Synth. Met. 2010, 160, 1143-1147. [CrossRef]

61. Wang, X.Y.; Feng, G.Y.; Li, M.J.; Ge, M.Q. Effect of PEDOT:PSS content on structure and properties of PEDOT:PSS/poly(vinyl alcohol) composite fiber. Polym. Bull. 2018, 76, 2097-2111. [CrossRef]

62. Hassan, M.M.; Tucker, N.; Le Guen, M.J. Thermal, mechanical and viscoelastic properties of citric acid-crosslinked starch/cellulose composite foams. Carbohydr. Polym. 2020, 230, 115676-115685. [CrossRef]

63. Li, L.; Li, X.; Du, M.; Guo, Y.; Li, Y.; Li, H.; Yang, Y.; Alam, F.E.; Lin, C.-T.; Fang, Y. Solid-phase coalescence of electrochemically exfoliated graphene flakes into a continuous film on copper. Chem. Mater. 2016, 28, 3360-3366. [CrossRef]

64. Ploypetchara, N.; Suppakul, P.; Atong, D.; Pechyen, C. Blend of polypropylene/poly(lactic acid) for medical packaging application: Physicochemical, thermal, mechanical, and barrier properties. Energy Procedia 2014, 56, 201-210. [CrossRef]

65. Boroumand, Y.; Razmjou, A.; Moazzam, P.; Mohagheghian, F.; Eshaghi, G.; Etemadifar, Z.; Asadnia, M.; Shafiei, R. Mussel inspired bacterial denitrification of water using fractal patterns of polydopamine. J. Water Process Eng. 2020, 33, 101105-101115. [CrossRef]

66. Chang, H.C.; Sun, T.; Sultana, N.; Lim, M.M.; Khan, T.H.; Ismail, A.F. Conductive PEDOT:PSS coated polylactide (PLA) and poly(3-hydroxybutyrate-co-3-hydroxyvalerate) (PHBV) electrospun membranes: Fabrication and characterization. Mater. Sci. Eng. C Mater. Biol. Appl. 2016, 61, 396-410. [CrossRef]

67. Luo, R.; Li, H.; Du, B.; Zhou, S.; Zhu, Y. A simple strategy for high stretchable, flexible and conductive polymer films based on PEDOT:PSS-PDMS blends. Org. Electron. 2020, 76, 105451-105458. [CrossRef]

68. Gholampour, N.; Brian, D.; Eslamian, M. Tailoring characteristics of PEDOT:PSS coated on glass and plastics by ultrasonic substrate vibration post treatment. Coatings 2018, 8, 337. [CrossRef]

69. Mofokeng, J.P.; Luyt, A.S.; Tábi, T.; Kovács, J. Comparison of injection moulded, natural fibre-reinforced composites with PP and PLA as matrices. J. Thermoplast. Compos. Mater. 2011, 25, 927-948. [CrossRef]

70. Kowalczyk, M.; Piorkowska, E.; Kulpinski, P.; Pracella, M. Mechanical and thermal properties of PLA composites with cellulose nanofibers and standard size fibers. Compos. Part A Appl. Sci. Manuf. 2011, 42, 1509-1514. [CrossRef]

Publisher's Note: MDPI stays neutral with regard to jurisdictional claims in published maps and institutional affiliations.

(C) 2020 by the authors. Licensee MDPI, Basel, Switzerland. This article is an open access article distributed under the terms and conditions of the Creative Commons Attribution (CC BY) license (http://creativecommons.org/licenses/by/4.0/). 